\title{
Impacts of Predicting the Liquid Fraction of Mixed-Phase Particles on the Simulation of an Extreme Freezing Rain Event: The 1998 North American Ice Storm
}

\author{
MÉlissa Cholette AND Julie M. ThÉRIAUlt \\ Centre pour l'Étude et la Simulation du Climat à l'Échelle Régionale, Department of Earth and Atmospheric \\ Sciences, Université du Québec à Montréal, Montreal, Quebec, Canada \\ JASON A. MiLBRANDT \\ Meteorological Research Division, Environment and Climate Change Canada, Dorval, Quebec, Canada \\ HUGH MORRISON \\ National Center for Atmospheric Research, Boulder, Colorado
}

(Manuscript received 28 January 2020, in final form 24 May 2020)

\begin{abstract}
A prognostic equation for the liquid fraction of mixed-phase particles has been recently added to the Predicted Particle Properties (P3) bulk microphysics scheme. Mixed-phase particles are necessary to simulate key microphysical processes leading to various winter precipitation types, such as ice pellets and freezing rain. To illustrate the impacts of predicting the bulk liquid fraction, the 1998 North American Ice Storm is simulated using the Weather Research and Forecasting (WRF) Model with the modified P3 scheme. It is found that simulating partial melting by predicting the bulk liquid fraction produces higher mass and number mixing ratios of rain. This leads to smaller rain sizes reaching the refreezing layer as well as a decrease in the freezing rain accumulation at the surface by up to $30 \%$ in some locations compared to when no liquid fraction is predicted. The increase in fall speed and density and decrease of particle diameter during partial melting combined with an improved representation of the refreezing process in the modified P3 leads to generally higher total solid surface precipitation rates than using the original P3 scheme. There is also an increase of solid precipitation in regions of ice pellet accumulation. Overall, the simulation of mixed-phase particles notably impacts the vertical and spatial distributions of precipitation properties.
\end{abstract}

\section{Introduction}

During cold seasons, several types of precipitation such as snow, wet snow, ice pellets, freezing rain, and rain can reach the surface when temperatures are near $0^{\circ} \mathrm{C}$ (e.g., Stewart 1985; Schuur et al. 2012; Frick et al. 2013; Stewart et al. 2015; Ikeda et al. 2017; Tobin and Kumjian 2017). Wet snow, ice pellets, and freezing rain can lead to ice accumulation on surfaces causing major power outages, interruptions to land and air transportation, damage to vegetation, and injuries to people (Lecompte et al. 1998; King and Laplante 2005; Chang

¿ Denotes content that is immediately available upon publication as open access.

Corresponding author: Melissa Cholette, cholette.melissa@ courrier.uqam.ca et al. 2007; Kringlebotn Nygaard et al. 2013). It is therefore important to improve their forecasts with more accurate numerical tools (Reeves et al. 2014; Reeves 2016; Ikeda et al. 2017).

Many types of precipitation can form while falling through a temperature profile composed of a warm layer aloft $\left(T>0^{\circ} \mathrm{C}\right)$ and cold layer $\left(T<0^{\circ} \mathrm{C}\right)$ below it, near the surface. While falling through the melting layer aloft, solid precipitation particles melt partially or completely. If they melt only partially upon reaching the top of the refreezing layer, the remaining ice fraction within the particle initiates freezing to produce ice pellets (Thériault and Stewart 2010). In contrast, if particles melt completely, supercooled drops may not refreeze before reaching the surface, producing freezing rain. Supercooled drops in the refreezing layer can also interact with locally produced ice crystals to initiate freezing, which also produces ice 
pellets (Hanesiak and Stewart 1995). This process can reduce the amount of freezing rain at the surface (Carmichael et al. 2011; Barszcz et al. 2018).

Accurate prediction of frozen precipitation is challenging in numerical weather prediction (NWP) models because it involves the need to parameterize mixedphase particles formed when temperatures are near $0^{\circ} \mathrm{C}$ (Frick et al. 2013). The main challenges are associated with the differentiation of surface precipitation types and their transition (Ralph et al. 2005; Reeves et al. 2014) as well as their validation with observations (Reeves 2016; Landolt et al. 2019). The various local and synoptic environmental conditions of winter storms influence several processes important for precipitation type forecasting (e.g., Rauber et al. 1994; Ramos da Silva et al. 2006; Petrolito 2005; Descurieux 2010; Finch 2011; Hosek et al. 2011; Arnott and Chamberlain 2014; Kumjian and Schenkman 2014). Small errors in temperature and humidity fields can lead to an incorrect prediction of the surface precipitation type (Thériault et al. 2010; Frick et al. 2013). Recently, there have been more efforts to improve forecasting of winter precipitation types, such as freezing rain and ice pellets (e.g., Hux et al. 2001; Cheng et al. 2004; Milbrandt et al. 2012; Kringlebotn Nygaard et al. 2013; Forbes et al. 2014; Benjamin et al. 2016; Ikeda et al. 2017; Gascón et al. 2018; Thielke 2018). However, most of these studies used diagnostic methods to determine the surface precipitation types (e.g., based on temperature or wet-bulb temperature profiles) and very few used the explicit prediction of mixed-phase particles (Reeves et al. 2016; Thompson 2019; Xu et al. 2019).

Typically, hydrometeors composed of only pure ice (e.g., bulk snow, hail, graupel, cloud ice) and pure liquid (e.g., rain, cloud droplets) are represented in microphysics schemes (e.g., Milbrandt and Yau 2005; Thompson et al. 2008). The melted mass of melting ice-phase hydrometeors is converted immediately to rain, leading to a sharp increase in fall speed (from $\sim 1$ to $\sim 5 \mathrm{~m} \mathrm{~s}^{-1}$; when bulk snow is melting), which impacts trajectories of precipitation particles and distributions of latent heating and cooling (Henson et al. 2011, hereafter H11). Most bulk microphysics schemes include freezing processes that are assumed to occur instantaneously when an ice nucleus is encountered. However, refreezing of partially melted ice particles is a gradual process, as is melting (e.g., Zerr 1997; Hindmarsh et al. 2003; Gibson and Stewart 2007; Stewart et al. 2015; Nagumo et al. 2019) and is not represented in most bulk schemes.

To represent correctly microphysical processes leading to freezing rain and ice pellets, it is necessary to predict partial melting of ice particles (Thériault et al.
TABLE 1. List of symbols for variables and parameters.

\begin{tabular}{llc}
\hline \hline Symbol & \multicolumn{1}{c}{ Description } & Units \\
\hline$B_{i, \text { rim }}$ & Rime volume mixing ratio of ice & $\mathrm{m}^{3} \mathrm{~kg}^{-1}$ \\
$D_{m}$ & Mean mass-weighted diameter of ice & $\mathrm{cm}$ \\
$D_{r}$ & $\begin{array}{l}\text { Mean mass-weighted diameter of rain or } \\
\text { freezing rain }\end{array}$ & $\mathrm{mm}$ \\
& Bulk liquid mass fraction & - \\
$F_{i, \text { liq }}$ & Bulk rime mass fraction & - \\
$F_{i, \text { rim }}$ & Total ice number mixing ratio & $\mathrm{kg}^{-1}$ \\
$N_{i, \text { tot }}$ & Rain of freezing rain number mixing ratio & $\mathrm{kg}^{-1}$ \\
$N_{\text {rain }}$ & Rime density & $\mathrm{kg} \mathrm{m}^{-3}$ \\
$\rho_{i, \text { rim }}$ & Mean mass-weighted density of ice & $\mathrm{kg} \mathrm{m}^{-3}$ \\
$\rho_{m}$ & Cloud mass mixing ratio & $\mathrm{g} \mathrm{kg}^{-1}$ \\
$q_{\text {cloud }}$ & Vapor deposition mass mixing ratio & $\mathrm{g} \mathrm{kg}^{-1}$ \\
$q_{i, \text { dep }}$ & Refreezing rate & $\mathrm{g} \mathrm{kg}^{-1} \mathrm{~s}^{-1}$ \\
$Q_{l, \text { frz }}$ & Liquid mass mixing ratio accumulated & $\mathrm{g} \mathrm{kg}^{-1}$ \\
$q_{i, \text { liq }}$ & $\quad$ on ice & \\
$q_{i, \text { rim }}$ & Rime mass mixing ratio & $\mathrm{g} \mathrm{kg}^{-1}$ \\
$q_{i, \text { tot }}$ & Total mass mixing ratio of ice and mixed- & $\mathrm{g} \mathrm{kg}^{-1}$ \\
& phase particles & \\
$Q_{\text {mlt }}$ & Total melting rate & $\mathrm{g} \mathrm{kg}^{-1} \mathrm{~s}^{-1}$ \\
$q_{\text {rain }}$ & Rain or freezing rain mass mixing ratio & $\mathrm{g} \mathrm{kg}^{-1}$ \\
$q_{v}$ & Water vapor mass mixing ratio & $\mathrm{g} \mathrm{kg}^{-1}$ \\
$T$ & Air temperature & ${ }^{\circ} \mathrm{C}$ \\
\hline & &
\end{tabular}

2006; Thériault and Stewart 2010). The explicit representation of mixed-phase particles in a bulk microphysics scheme involves tracking the bulk liquid fraction $\left(F_{i, \text { liq }}\right.$; all symbols are defined in Table 1$)$ of these particles in time and space; $F_{i, \text { liq }}$ represents the liquid mass proportion of the mixed-phase particle distribution and is mainly driven by phase changes and collisions among particles. To predict $F_{i, \text { liq }}$, the liquid mass mixing ratio on ice particles $\left(q_{i, \text { liq }}\right)$ must be included as a prognostic variable in the scheme. The mixing ratio $q_{i, \text { liq }}$ is an extensive, conserved quantity that can be advected and diffused, whereas $F_{i \text {,iq }}$ is not. Then $F_{i \text {,iq }}$ is calculated as the ratio of $q_{i, \text { liq }}$ and the total mass mixing ratio $\left(q_{i, \text { tot }}\right)$. Cholette et al. (2019) (hereafter C19) added a prognostic equation for $q_{i, \text { liq }}$ in the Predicted Particle Properties (P3) bulk microphysics scheme of Morrison and Milbrandt (2015) and Milbrandt and Morrison (2016). The P3 scheme has a user-specified number of "free" ice categories, rather than several predefined ice-phase categories as in traditional schemes. Each category can, in principle, represent any type of frozen hydrometeor. Several bulk physical ice properties, such as the mean density $\left(\rho_{m}\right)$, the mean dimension $\left(D_{m}\right)$ and the rime mass fraction $\left(F_{i, \text { rim }}\right)$ are predicted. The prediction of $F_{i, \text { liq }}$ in the single-category configuration of $\mathrm{P} 3$ was tested using a one-dimensional cloud model in $\mathrm{C} 19$.

The objective of this study is to investigate the impacts of predicting $F_{i, \text { liq }}$ in simulations of the precipitation types produced during a major winter storm. To 
accomplish this, high-resolution numerical simulations of an extreme freezing rain event are conducted using the modified P3 scheme with predicted $F_{i, \text { liq }}$ and the original P3 scheme (Morrison and Milbrandt 2015; Milbrandt and Morrison 2016). To our knowledge, this is the first time that such a bulk microphysics scheme with mixed-phase particles and prediction of $F_{i, \text { liq }}$ has been tested in a real-case simulation involving many winter precipitation types.

The case examined is the 1998 Ice Storm that occurred from 4 to 10 January 1998, during which snow, ice pellets, and freezing rain fell over a widespread area in the northeastern United States and the eastern Canadian provinces. Nearly $100 \mathrm{~mm}$ of freezing rain accumulated at the surface in southern Quebec. This event is considered to be one of the costliest natural disasters in Canadian history (Lecompte et al. 1998). This case was chosen mainly because it is well documented (Laflamme and Périard 1998; Lecompte et al. 1998; Milton and Bourque 1999; Cober et al. 2001; Gyakum and Roebber 2001; Roebber and Gyakum 2003, hereafter RG03; Henson et al. 2007; H11). This is also the first time that the 1998 Ice Storm case has been simulated using a very high-resolution atmospheric model, to our knowledge. Our focus is mainly on the similarities and differences in simulated precipitation types and parameterized microphysical processes with and without predicting $F_{i, \text { liq }}$.

The remainder of the paper is organized as follows. Section 2 describes the experimental design including the model configuration, the P3 microphysics scheme and the methodology for comparing the simulations and observations. Section 3 gives the meteorological overview of the simulated storm and comparison with some observations. Section 4 investigates the impacts of predicting $F_{i \text {,liq }}$ in simulated precipitation types, in particular freezing rain. Section 5 presents the conclusions.

\section{Experimental design}

\section{a. Model configuration}

This study uses the Weather Research and Forecasting (WRF) Model, version 3.9.1.1 (Skamarock and Klemp 2008). WRF is a nonhydrostatic compressible atmospheric model. The domain for our simulations, shown in Fig. 1, covers the region of southern Quebec extending from Lake Ontario to almost all of New Brunswick. It has $352 \times 352$ horizontal grid points and 3-km horizontal grid spacing. The red square in Fig. 1 shows the analysis domain, which accounts for the spinup of finescale motion along the lateral domain boundaries (e.g., Matte et al. 2017). The initial and lateral boundary conditions are provided by the North American Regional Reanalysis (NARR; Mesinger et al. 2006). The simulations were

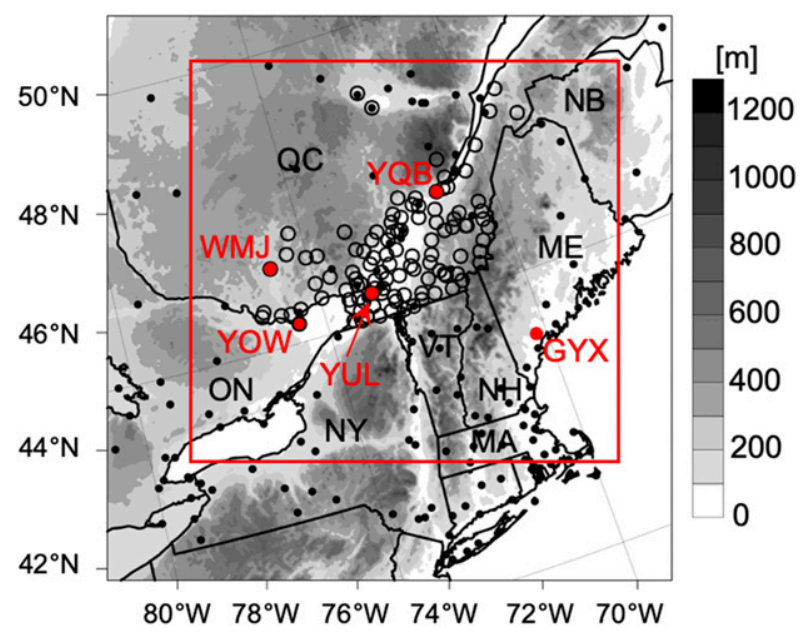

FIG. 1. Simulation domain elevation (gray shading, $m$ ) and location of the analysis domain (red square). Also shown are the locations of the observation stations for the 1998 Ice Storm meteorological overview of total accumulated precipitation types (circles) from Milton and Bourque (1999) and surface atmospheric variables (dots) from the University of Wyoming website (http:// weather.uwyo.edu/). Specific stations are highlighted: Montreal Pierre-Elliott-Trudeau International Airport (YUL), Ottawa Airport (YOW), Maniwaki (WMJ), Gray (GYX), and Quebec Jean-Lesage Airports (YQB) and are described in Table 2.

driven solely by NARR without data assimilation. This dataset is available every $3 \mathrm{~h}$ over North America at $32 \mathrm{~km}$ horizontal grid spacing. There are 56 vertical levels with a vertical grid spacing varying from 60 to $320 \mathrm{~m}$ in the first $2 \mathrm{~km}$ and from 320 to $340 \mathrm{~m}$ between 2 and $16 \mathrm{~km}$. The simulated period is from 0600 UTC 4 January to 0600 UTC 10 January 1998. The model time step is $10 \mathrm{~s}$ and output was stored every $30 \mathrm{~min}$.

Physics parameterizations besides microphysics include radiation, planetary boundary layer/turbulent mixing, and surface processes. Shortwave and longwave radiations are calculated using the general circulation model version of the Rapid Radiative Transfer Model (Iacono et al. 2008) with a $10 \mathrm{~min}$ radiation time step. The Yonsei University nonlocal planetary boundary layer scheme of Hong et al. (2006) is employed. Surface processes are calculated using the five-layer thermal diffusion scheme of Dudhia (1996). Two simulations are performed using the P3 bulk microphysics scheme. The first simulation uses the original configuration, with one ice category, hereafter referred as P3_ORIG. The second simulation uses the modified $\mathrm{P} 3$ scheme including the predicted $F_{i, \text { liq }}(\mathrm{C} 19)$, hereafter referred as P3_MOD.

\section{b. The P3 microphysics scheme}

This section summarizes the main differences between P3_MOD and P3_ORIG. More details can be found in Morrison and Milbrandt (2015) for P3_ORIG 
and in C19 for P3_MOD. Both schemes have two liquid categories: cloud and rain. The solid category is parameterized differently compared to most bulk microphysics schemes. Similar to Morrison and Grabowski (2008), P3 evolves particle properties and bulk ice type for "free" categories using four prognostic variables per ice category. In contrast, most bulk schemes separate solid hydrometeors into categories corresponding to fixed ice types (e.g., snow, graupel and hail) and use poorly constrained conversion processes between the solid categories. P3 can include more than one ice category as detailed in Milbrandt and Morrison (2016), but the single ice category version is used here. The four prognostic ice variables per category in P3_ORIG are: the total ice mass $\left(q_{i, \text { tot }}\right.$, in $\left.\mathrm{kg} \mathrm{kg}^{-1}\right)$, the total number $\left(N_{i, \text { tot }}\right.$, in $\left.\mathrm{kg}^{-1}\right)$, the rime mass $\left(q_{i, \text { rim }}\right.$, in $\left.\mathrm{kg} \mathrm{kg}^{-1}\right)$ and the rime volume $\left(B_{i, \text { rim }}\right.$, in $\left.\mathrm{m}^{3} \mathrm{~kg}^{-1}\right)$ mixing ratios. P3_MOD has a fifth prognostic variable, the liquid mass mixing ratio accumulated on ice $\left(q_{i, \text { liq }}\right.$, in $\left.\mathrm{kg} \mathrm{kg}^{-1}\right)$. Hence, the total mass mixing ratio of ice and mixed-phase particles is $q_{i, \text { tot }}=q_{i, \text { rim }}+q_{i, \text { dep }}$ in P3_ORIG and $q_{i, \text { tot }}=q_{i, \text { rim }}+$ $q_{i, \mathrm{dep}}+q_{i, \mathrm{liq}}$ in P3_MOD, where $q_{i, \mathrm{dep}}$ is the mass mixing ratio of vapor deposition growth. Several bulk properties, including the rime and liquid (for P3_MOD) mass fractions, the bulk density, the bulk rime density, the mean size, and the mean number and mass-weighted fall speeds are predicted from these conserved prognostic variables. The bulk rime mass fraction is $F_{i, \text { rim }}=q_{i, \text { rim }} /\left(q_{i, \text { rim }}+q_{i, \text { dep }}\right)$ (for both) and the bulk liquid mass fraction in P3_MOD is $F_{i, \text { liq }}=q_{i, \text { liq }} /\left(q_{i, \text { rim }}+q_{i, \text { dep }}+q_{i, \text { liq }}\right)$.

The main assumptions for the implementation of $F_{i, \text { liq }}$ in P3_MOD are summarized as follows. First, the liquid mass fraction of particles does not vary with size (as for the rime mass fraction) and is given by the predicted bulk liquid mass fraction $\left(F_{i, \text { liq }}\right)$. Second, it is assumed that the liquid water is uniformly distributed around an ice core. For simplicity and due to lack of observations, ice cores are assumed to have the same properties (mass, projected area, capacitance, ventilation coefficient and so on) as in P3_ORIG. It is assumed that some processes, such as melting and sublimation, depend on the ice core properties while other processes, such as refreezing and vapor condensation of $q_{i, \text { liq }}$, depend on properties of the whole mixed-phase particle. For both the ice core and the whole particle, the particle size distribution is given by

$$
N\left(D_{x}\right)=N_{0} D_{x}^{\mu} \exp \left(-\lambda D_{x}\right),
$$

where $N_{0}$ is the intercept parameter, $\mu$ is the shape parameter, and $\lambda$ is the slope parameter. The shape parameter is a function of the slope parameter following Heymsfield (2003):
TABLE 2. List of stations.

\begin{tabular}{llcrr}
\hline \hline Code & \multicolumn{1}{c}{ Station name } & $\begin{array}{r}\text { Lat } \\
\left({ }^{\circ} \mathrm{N}\right)\end{array}$ & $\begin{array}{r}\text { Lon } \\
\left({ }^{\circ} \mathrm{W}\right)\end{array}$ & $\begin{array}{r}\text { Elev } \\
(\mathrm{m})\end{array}$ \\
\hline GYX & Gray & 43.90 & 70.25 & 125 \\
WMJ & Maniwaki & 46.30 & 76.01 & 189 \\
YHU & Saint-Hubert airport & 45.52 & 73.42 & 27 \\
YMX & Mirabel airport & 45.68 & 74.03 & 82 \\
YOW & Ottawa airport & 45.32 & 75.67 & 114 \\
YQB & Quebec Jean-Lesage airport & 46.80 & 71.38 & 74 \\
YUL & $\begin{array}{l}\text { Pierre-Elliott-Trudeau } \\
\text { airport }\end{array}$ & 45.47 & 73.75 & 36 \\
& & & & \\
\hline
\end{tabular}

$$
\mu=0.00191 \lambda^{0.8}-2,
$$

where $\lambda$ has units of $\mathrm{m}^{-1}$, and $D_{x}$ is the ice core size $(x=d)$ for processes depending on the ice core and the whole particle size $(x=p)$ for processes acting on the entire mixed-phase particle. Each microphysical process rate is then integrated over the appropriate particle size distribution to calculate bulk rates. The differences between P3_MOD and P3_ORIG in formulations of microphysical processes are summarized in the appendix and elaborated in C19.

\section{c. Methodologies comparing the simulations and with the observations}

In section 3 , it is shown that simulated atmospheric and precipitation fields of the storm are well reproduced by the simulations and we focus on the main differences relative to the observations. Observed total accumulations for various precipitation types are from Milton and Bourque (1999) (locations shown by circles in Fig. 1; see Table 2 for a list of the stations highlighted in red). The comparison of accumulated precipitation between the simulations and the observations is as follows. In both the P3_ORIG and P3_MOD simulations, precipitation outputs are total solid and total liquid, in which rain and freezing rain are included. The total precipitation is then the sum of total liquid and total solid. Also, for both P3_MOD and P3_ORIG, freezing rain is assumed to be supercooled rain when the lowest model level temperature is $<0^{\circ} \mathrm{C}$. In P3_MOD, to differentiate between snow, ice pellets, and wet snow, we applied some basic assumptions. Ice pellets are solid precipitation when the predicted liquid fraction aloft is $>0$ and temperature of the lowest model level is $<0^{\circ} \mathrm{C}$. Wet snow is solid precipitation when the lowest model level liquid fraction is $>0$ and temperature of the lowest model level is $>0^{\circ} \mathrm{C}$. Note that wet snow and ice pellets can be unrimed, partially rimed or completely rimed $\left(0 \leq F_{i, \text { rim }} \leq 1\right)$. Snow in P3_MOD is then the total solid precipitation minus ice pellets and wet snow. The precipitation type classification is done at each model time step when 
hydrometeors are present and stored at $30 \mathrm{~min}$ intervals. In P3_ORIG, wet snow and ice pellets cannot be separated from total solid precipitation based on the physical properties of ice particles unlike in P3_MOD, so the assumptions used to determine these precipitation types in P3_MOD are only based on $F_{i, \text { liq }}$ and temperature near the surface. Also note that validation of these precipitation types (e.g., ice pellets and wet snow) with observations is difficult because ice pellets are usually reported with snow or freezing rain and wet snow is reported as snow. This is the reason why observed total solid precipitation does not separate ice pellets from snow. All precipitation accumulations are in liquid-equivalent (in $\mathrm{mm}$ ), therefore, total solid, snow, ice pellets, and wet snow are given in terms of melted equivalent in millimeters as well. Observed surface temperatures, surface horizontal winds, sea level pressures as well as vertical profiles of temperature at Maniwaki (WMJ) and Gray (GYX) stations have been taken from the University of Wyoming website (dots in Fig. 1) for comparison with the simulations.

In section 4, the impacts of predicting the liquid fraction on simulating precipitation types are investigated. To do so, a comparison between P3_MOD and P3_ORIG of the accumulated precipitation, temporal evolution of precipitation rates and vertical structures of particle size distributions is made over four subregions of interest. The choice of the regions was based on the location of differences between P3_MOD and P3_ORIG over the simulated domain, explained in more detail later. Also, the precipitation characteristics aloft, such as mass mixing ratios, are analyzed with two vertical cross sections over the subregions.

\section{Overview of the simulated 1998 Ice Storm}

\section{a. Temperature and wind fields}

The successive passage of low pressure systems and a quasi-stationary front extending from southern Ontario to the Maritime Provinces led to relatively warm and moist airflow aloft producing favorable conditions for freezing rain and ice pellets (RG03). Two periods of significant freezing rain accumulation occurred (H11). The first icing period was from 1200 UTC 5 January to 0000 UTC 7 January 1998 and the second ice period was longer, extending from 0000 UTC 8 January to 0000 UTC 10 January 1998. Different synoptic conditions characterized these two icing periods. The first period was associated with frontogenesis within a baroclinic zone established with the approach of a trough, whereas the baroclinic zone was associated with a well-developed cyclone during the second icing period (RG03).

The low-level temperature in southern Quebec remained below $0^{\circ} \mathrm{C}$ during the two icing periods as shown in Fig. 2. The locations of the $0^{\circ} \mathrm{C}$ isotherms are well reproduced by both simulations compared to observations with some differences over Lake Ontario and New Hampshire (NH) during the second icing period. In general, there is a small warm bias for both icing periods: $\sim 0.67^{\circ} \mathrm{C}$ for the first icing period and $\sim 0.12^{\circ} \mathrm{C}$ for the second icing period and very similar biases for P3_MOD and P3_ORIG. The warm biases between the simulations and the observations are the greatest $\left(\sim 2^{\circ}-4^{\circ} \mathrm{C}\right)$ at stations located north of the analysis domain during the first icing period (e.g., observed stations with temperatures $<-14^{\circ} \mathrm{C}$ ) and at stations located in the Green Mountains (VT) for both icing periods (not shown). Sea level pressures are lower by about $\sim 2$ to $4 \mathrm{hPa}$ in the simulations compared to observations. For both icing periods, northeasterly lowlevel winds contributed to maintaining the cold air near the surface in the St. Lawrence River Valley (SLRV) and the Ottawa River Valley (Milton and Bourque 1999; RG03). Low-level winds were $\sim 1$ to $3 \mathrm{~m} \mathrm{~s}^{-1}$ higher during the second icing period compared to the first icing period (H11).

Windrose diagrams show that $10-\mathrm{m}$ horizontal winds were always north-northeasterly and east-northeasterly during the storm at Montreal (YUL) and Quebec (YQB), respectively (Fig. 3), and stronger at YQB than at YUL. The simulated intensities of low-level horizontal winds were slightly higher (lower) at YUL (YQB) with a northward rotation compared to observations (Fig. 3). Also, a wind flow from the south aloft (e.g., at elevations $>1-1.5 \mathrm{~km}$ ) occurred during the second icing period but not during the first period (see H11) (not shown).

A comparison between simulated and observed vertical profiles of temperature at two times during each icing period and at two locations (WMJ in southwestern Quebec and GYX in southern Maine; see Fig. 1) is shown in Fig. 4. At WMJ, the second icing period was short and only 1 sounding measured a melting layer aloft and a refreezing layer near the surface (at 1200 UTC 9 January 1998; Fig. 4c). At GYX, two soundings per icing period were characterized by a melting layer aloft and a refreezing layer near the surface. We present one time per icing period at GYX and the same time for the first icing period at WMJ. The temperature profiles are in general well reproduced by simulations, except for temperatures in the refreezing layer that are generally warmer in Figs. 4a-c. The model temperatures are generally warmer above the nose and the peak of the 

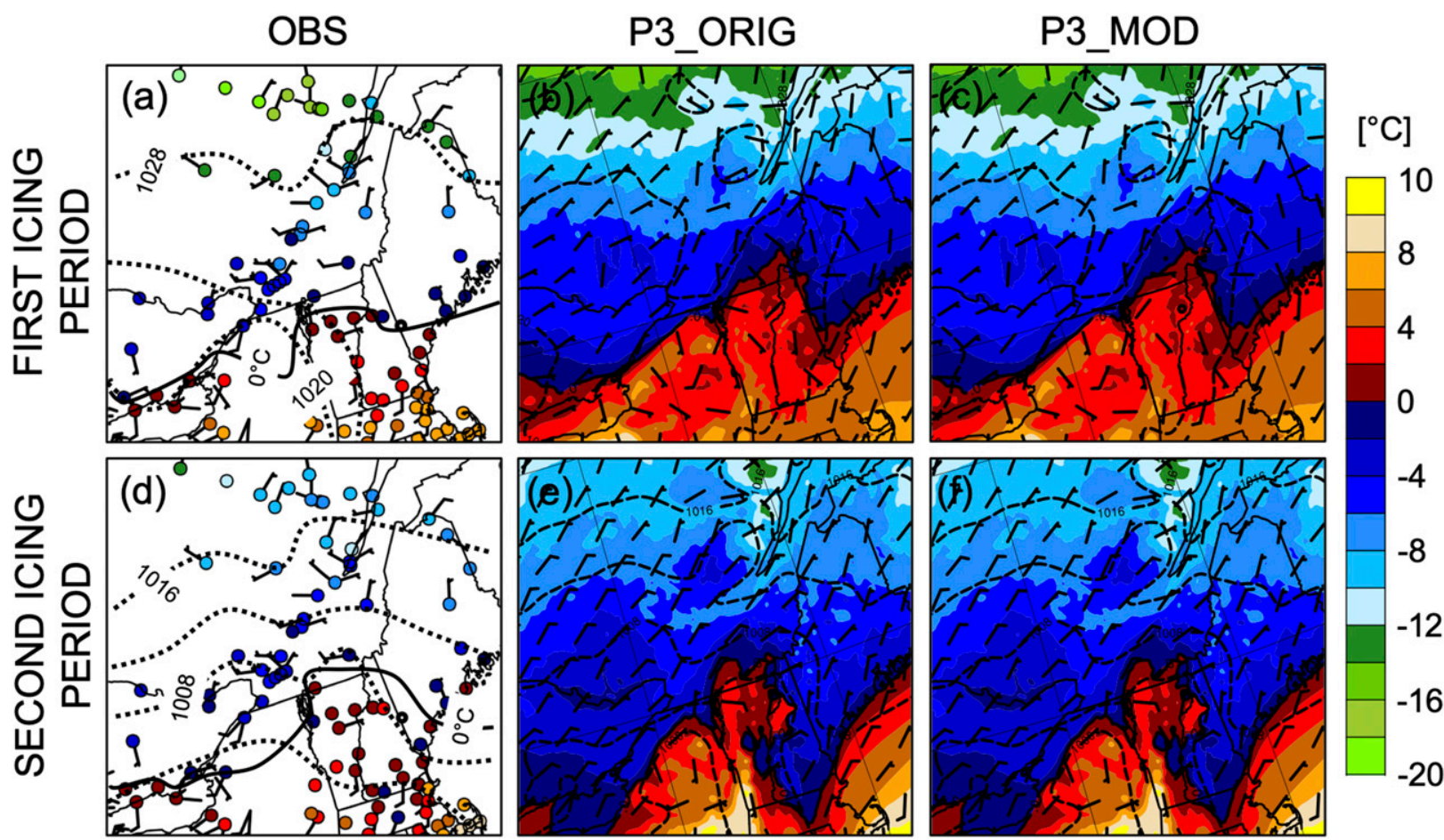

FIG. 2. (left) Observed surface temperature and (center) P3_ORIG and (right) P3_MOD temperature at the lowest model level timeaveraged during (a)-(c) the first icing period (from 0000 UTC 5 Jan 1998 to 0000 UTC 7 Jan 1998) and (d)-(f) the second icing period (from 0000 UTC 8 Jan 1998 to 0000 UTC $10 \mathrm{Jan} 1998$ ) in ${ }^{\circ} \mathrm{C}$ (color contours) and $0{ }^{\circ} \mathrm{C}$ isotherm (solid black). Also shown are the 10 -m wind barbs $\left(<0.1 \mathrm{~m} \mathrm{~s}^{-1}\right.$ for no barb, $2.5 \mathrm{~m} \mathrm{~s}^{-1}$ for half barb, and $5 \mathrm{~m} \mathrm{~s}^{-1}$ for full barb) and the sea level pressure (dotted, every $\left.4 \mathrm{hPa}\right)$ at (a) $-(\mathrm{c})$ 0000 UTC 6 Jan 1998 and (d)-(f) 0000 UTC 9 Jan 1998. Observation data are taken from the University of Wyoming website (http:// weather.uwyo.edu/).

warm nose is slightly colder at GYX (Figs. 4b,d). The height of the melting layer is higher at these locations during the second icing period (Figs. 4c,d) compared to the first period (Figs. 4a,b) in agreement with H11. However, the thickness of the melting layer aloft during the first icing period was nearly constant in time while it varied during the second period over southern Quebec (H11) (not shown). Differences between P3_MOD and P3_ORIG in the vertical profiles of temperature are small.

\section{b. Precipitation fields}

The accumulated precipitation types from the observations (Milton and Bourque 1999) and both simulations are shown in Fig. 5. The observed maximum amount of total precipitation of $133 \mathrm{~mm}$ over southern Quebec is underestimated by both simulations (Figs. 5ac). In contrast, observed amounts between 50 and $70 \mathrm{~mm}$ north of YUL are overestimated by P3_ORIG and P3 MOD (Figs. 5a,c). Similar results are obtained for total liquid (Figs. 5g-i) and freezing rain (Figs. 5j-1): an underestimation of large accumulations $(>90 \mathrm{~mm})$ and overestimation of small accumulations $(<70 \mathrm{~mm})$. The location of freezing rain maximum accumulation is shifted southwest compared to the observations in both simulations, but the maximum amount is well captured $(\sim 113 \mathrm{~mm})$. Observed patterns of total solid precipitation (Figs. 5d-f) and rain (Figs. 5m-o) are well reproduced by both simulations. The total solid maximum accumulation of $\sim 70 \mathrm{~mm}$ is near YQB in the observations as well as in the simulations. However, the small amounts of solid ( $\sim-10 \mathrm{~mm})$ near southern Quebec are not reproduced by either simulation. The bias and the root-mean-square error (RMSE) (Table 3) are of the same order of magnitude in P3_MOD and P3_ORIG. However, those of P3_MOD are systematically lower than P3_ORIG. The mean bias and the RMSE for freezing rain accumulations are reduced by $14 \%$ and $9.4 \%$, respectively, in P3_MOD compared to P3_ORIG. Also, for solid accumulations, P3_MOD improved by $87 \%$ the mean bias of P3_ORIG, though the biases for solid accumulations are very small for both simulations. The difference between both simulations and the observations is much larger than the difference between the two simulations, except for the solid accumulation bias, for which the differences are of the same order of magnitude. 

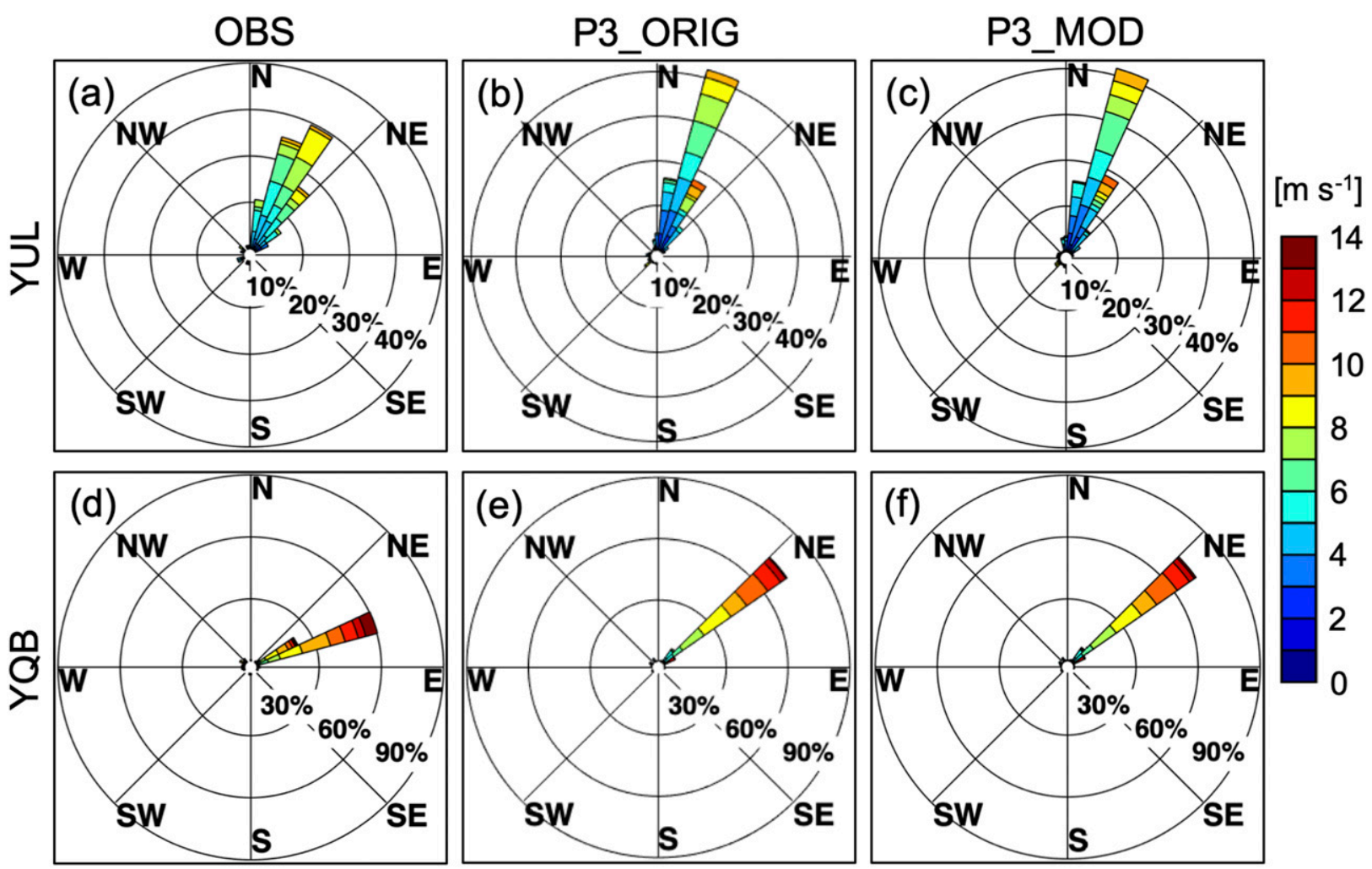

FIG. 3. (left) Observed, (center) P3_ORIG, and (right) P3_MOD time-averaged, over the simulation period (0600 UTC 4 Jan 1998 to 0600 UTC 10 Jan 1998), 10-m wind rose diagrams at (a)-(c) YUL and (d)-(f) YQB. The colors represent the wind intensities ( $\mathrm{m} \mathrm{s}^{-1}$ ) and the circles are the frequencies (\%) of each intensity-direction combination. Observation data are taken from the University of Wyoming website (http://weather.uwyo.edu/). Station locations are indicated in Fig. 1.

Time evolution of simulated surface precipitation rates and hourly observed precipitation types is shown at three stations in Canada (YQB, YUL, YOW; see Fig. 1) in Fig. 6. The two periods of significant freezing rain are well reproduced by the simulations. The precipitation type during the first icing period is mainly freezing rain, whereas during the second icing period it is more of a mixture of freezing rain and ice pellets, in particular at YUL, in agreement with H11. The second icing period is characterized by higher precipitation rates (and accumulations) compared to the first period, in particular at YOW, in agreement with RG03. For example, near Sherbrooke (southeast of YUL), observed freezing rain accumulation was 36 and $44 \mathrm{~mm}$ during the first and the second icing periods, respectively. In P3_MOD (P3_ORIG), at the same location, $33 \mathrm{~mm}(32 \mathrm{~mm})$ and $47 \mathrm{~mm}(48.5 \mathrm{~mm})$ of freezing rain accumulated during the first and second icing periods, respectively. There is a south-tonorth transition of precipitation types in the simulations and observations, such that there is more freezing rain in southern stations (YOW and YUL) and more snow (and ice pellets) at YQB. The mixture of wet snow and rain associated with both observed and simulated surface temperatures $>0{ }^{\circ} \mathrm{C}$ at YOW around 1200 UTC 8 January (Fig. 6c) is well captured by P3_MOD. Overall, the duration of ice pellets is lower in P3_MOD compared to observed, particularly at YUL (also illustrated in Figs. 5d-f). Differences between P3_MOD and P3_ORIG in precipitation rates are small, but freezing rain rate is reduced in $\mathrm{P} 3$ _MOD when ice pellets accumulate, in particular at YQB (Fig. 6a). These differences between P3_MOD and P3_ORIG are discussed in more detail in the next section.

\section{Differences between P3_MOD and P3_ORIG}

\section{a. Precipitation accumulation}

The impacts of predicting $F_{i, \text { liq }}$ in P3_MOD on simulated precipitation amounts and types are investigated in this section. Figure 7 shows the differences between P3_MOD and P3_ORIG in accumulated freezing rain (Fig. 7a) and solid precipitation (Fig. 7b). There is an overall decrease of freezing rain in P3_MOD, with a 
WMJ

(a) 1200 UTC 6 January

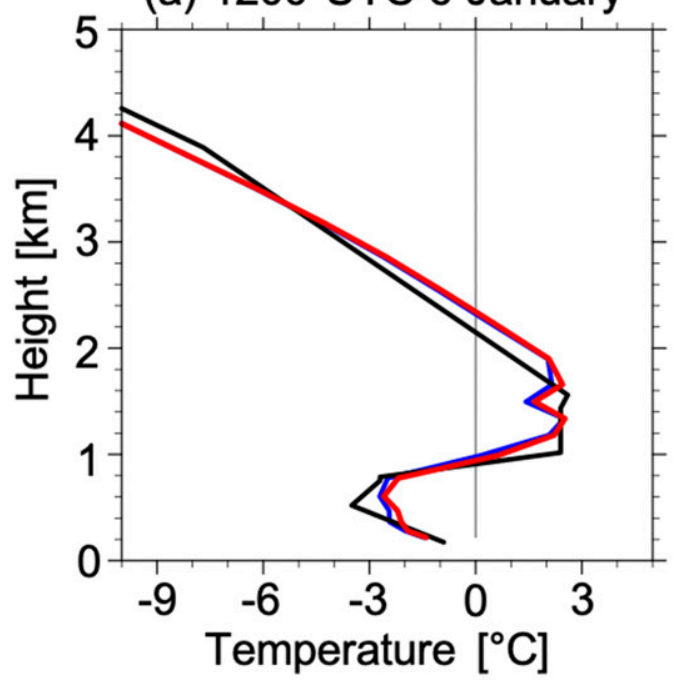

(c) 1200 UTC 9 January

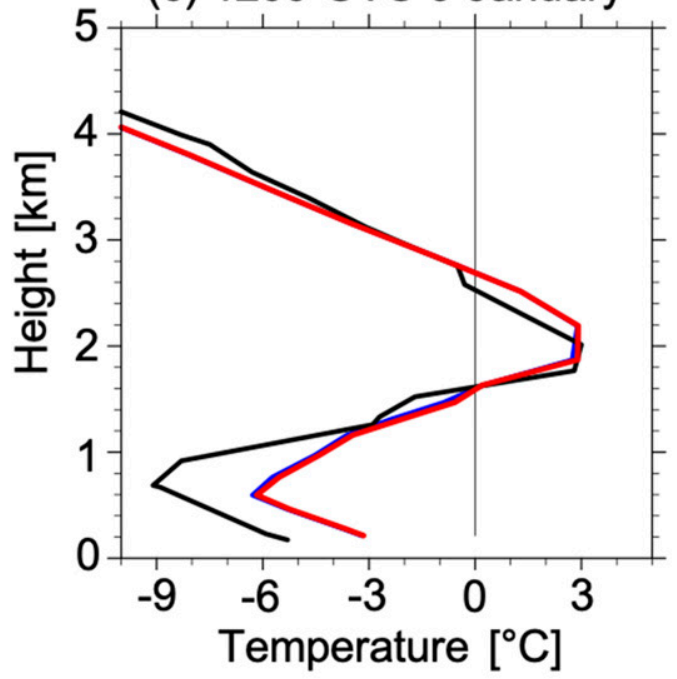

GYX

(b) 1200 UTC 6 January

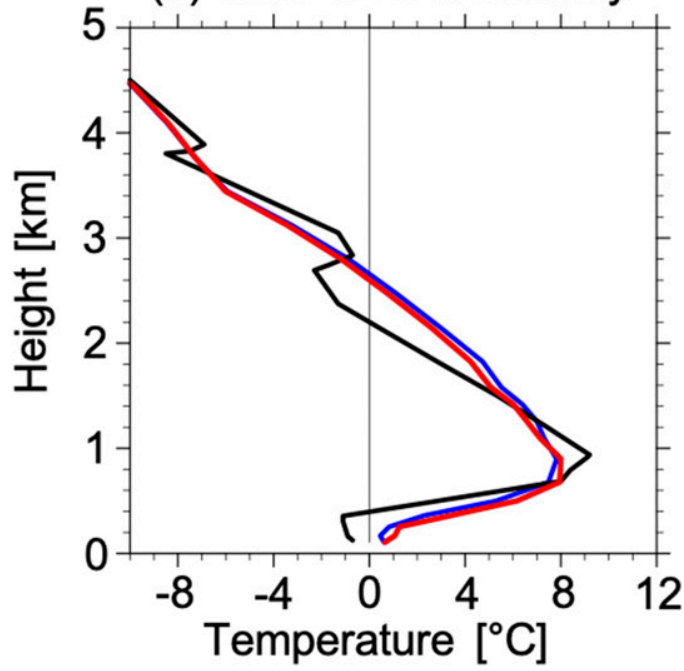

(d) 0000 UTC 9 January

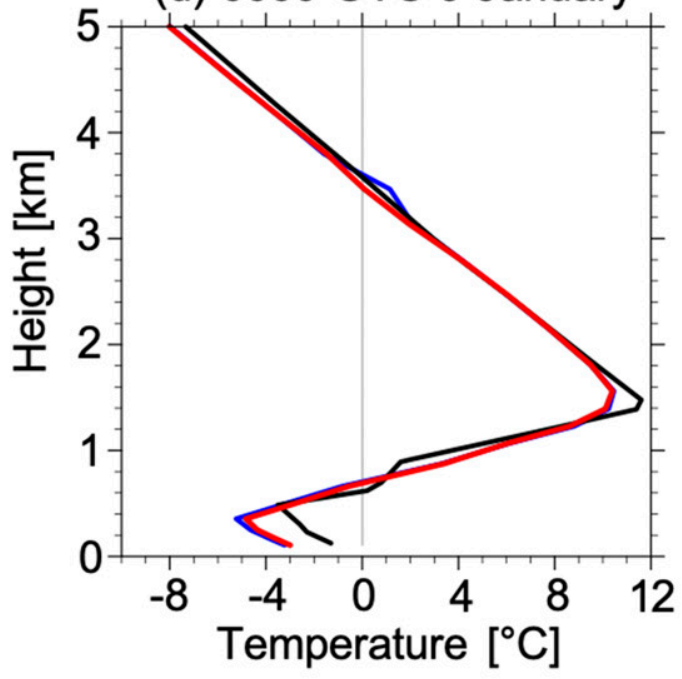

\section{OBS P3_ORIG}

P3_MOD

FIG. 4. Observed (black), P3_ORIG (blue), and P3_MOD (red) vertical profiles of temperature $\left({ }^{\circ} \mathrm{C}\right)$ at (a) 1200 UTC 6 Jan 1998 at WMJ, (b) 1200 UTC 6 Jan 1998 at GYX, (c) 1200 UTC 9 Jan 1998 at WMJ, and (d) 0000 UTC 9 Jan 1998 at GYX. Simulated profiles are taken at the grid point closest to the observation stations and observed profiles are taken from the University of Wyoming website (http://weather.uwyo.edu/). Station locations are indicated in Fig. 1.

general increase in solid precipitation. In Maine (ME), a decrease up to $25 \mathrm{~mm}$ in freezing rain accumulation occurs for P3_MOD compared to P3_ORIG. Figures 7c and 7d show P3_MOD's total accumulated wet snow and ice pellets, respectively. A widespread region of ice pellets is simulated during the storm. The maximum amount of ice pellets $(\sim 35 \mathrm{~mm})$ is located $\sim 60 \mathrm{~km}$ north of YUL. Only $\sim 0.2 \mathrm{~mm}$ of ice pellets accumulated at YUL itself. The maximum amount of wet snow $(\sim 10 \mathrm{~mm})$ is located near west of YOW, mainly accumulated during the second icing period. Wet snow also occurs in southeast Quebec and into the Green Mountains (VT) at 

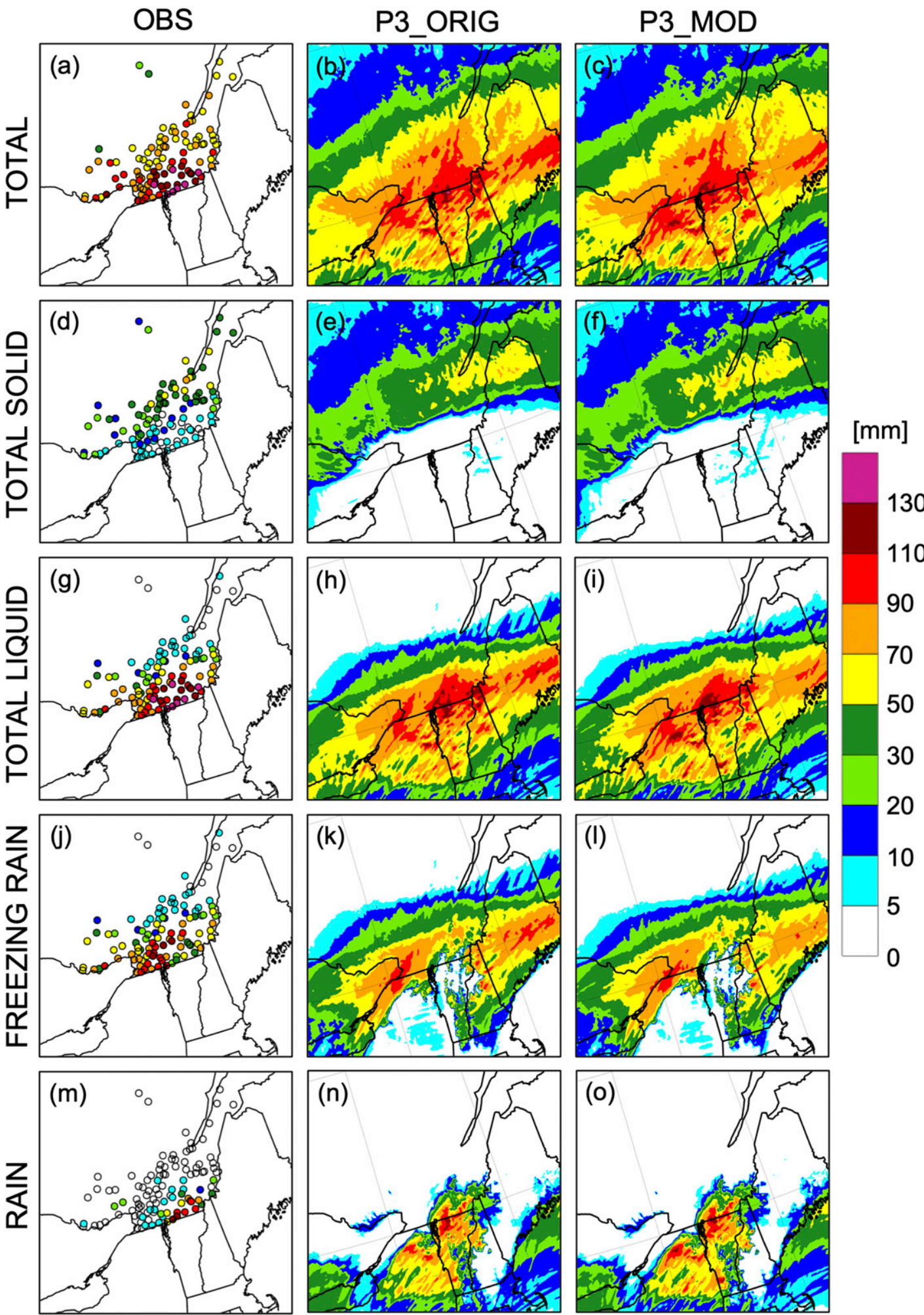

FIG. 5. (left) Observed, (center) P3_ORIG, and (right) P3_MOD accumulated precipitation (mm) from 0600 UTC 4 Jan 1998 to 0600 UTC 10 Jan 1998 of (a)-(c) total precipitation, (d)-(f) total solid precipitation, (g)-(i) total liquid precipitation, (j)-(l) freezing rain, and $(\mathrm{m})-(\mathrm{o})$ rain. 
TABLE 3. Bias and root-mean-square error (RMSE) ( $\mathrm{mm}$ ) of the simulated total accumulated precipitation compared to observations for the stations shown in Fig. 5.

\begin{tabular}{llcc}
\hline \hline & & P3_ORIG & P3_MOD \\
\hline Total & Bias & 14.2 & 14.1 \\
\multirow{3}{*}{ Total liquid } & RMSE & 25.4 & 24.8 \\
& Bias & 15.7 & 14.4 \\
Total solid & RMSE & 24.5 & 22.7 \\
& Bias & -1.5 & -0.2 \\
& RMSE & 10.4 & 10.35 \\
& Bias & 14.5 & 12.4 \\
& RMSE & 25.6 & 23.2 \\
\hline
\end{tabular}

different times but mainly at the beginning and the end of the simulated period. As seen in Fig. 7, the maximum differences between P3_MOD and P3_ORIG in accumulated freezing rain and solid precipitation occur where a mixture of ice pellets and freezing rain is produced by P3_MOD.

To investigate differences between P3_MOD and P3_ORIG in precipitation properties aloft and at the surface, four subregions (A to D) within the model domain are further analyzed (black squares in Figs. 7a,b). We define the four subregions of $3600 \mathrm{~km}^{2}$ within the model domain based on the differences between P3_MOD and P3_ORIG in surface amounts and precipitation types. Two subregions are located where the total accumulated freezing rain in P3_ORIG is $>50 \mathrm{~mm}$ and the two others are located where the total solid accumulation in P3_ORIG is $>25 \mathrm{~mm}$.

The subregion-averaged total accumulated precipitation for various precipitation types is shown in Fig. 8. Subregion A is associated with mainly freezing rain whereas subregion B is associated with a mixture of precipitation but mainly freezing rain. Subregion $C$ is located north of subregion A, with mainly solid precipitation and some ice pellets and freezing rain. Finally, the fourth subregion (D) is located northwest of subregion $\mathrm{B}$ and has nearly same accumulations at the surface as subregion C. According to Lecompte et al. (1998), 40$60 \mathrm{~mm}$ of freezing rain were reported at B, implying a model overestimation as well as in subregions $\mathrm{A}$ and $\mathrm{C}$ where more quantitative observational estimates are available (Fig. 8). For subregion D, it is not possible to

(a) YQB

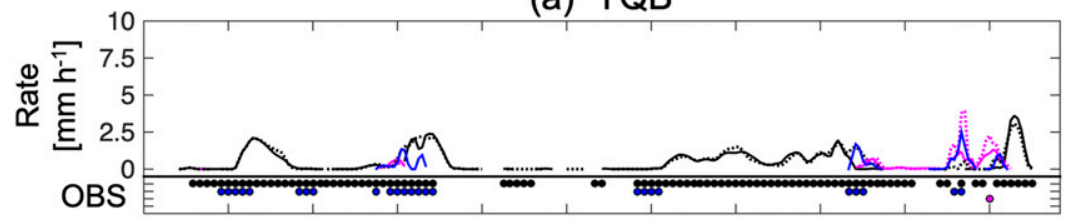

(b) YUL

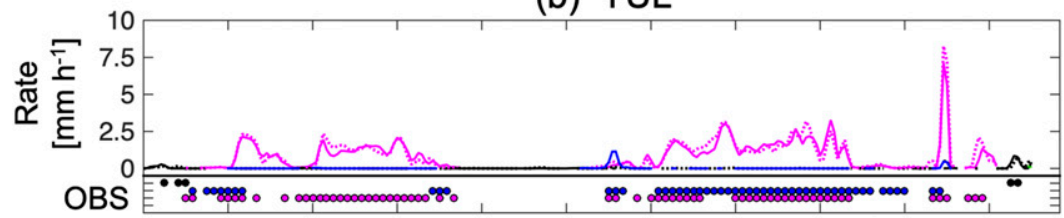

(c) YOW
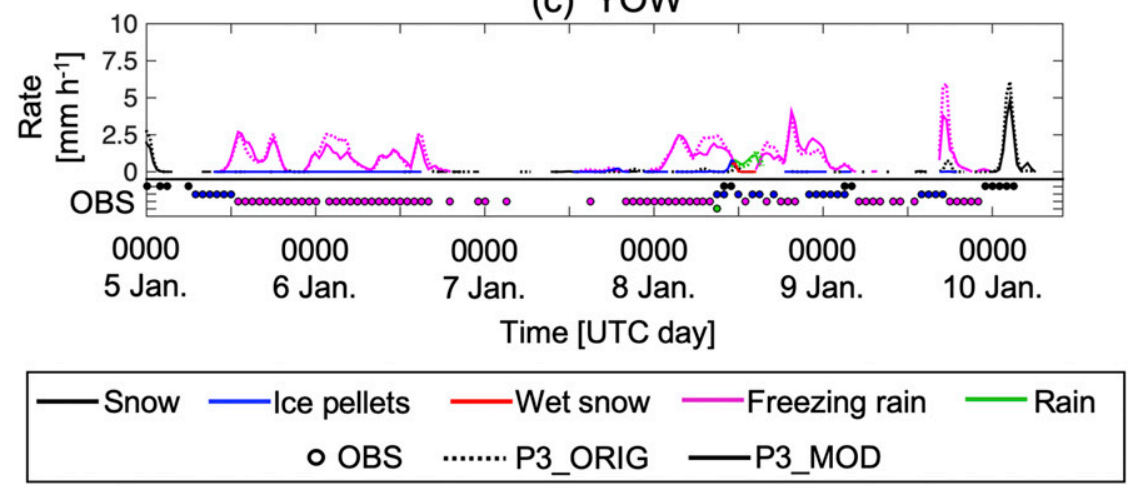

FIG. 6. Temporal evolution of P3_MOD (solid) and P3_ORIG (dotted), surface precipitation rates $\left(\mathrm{mm} \mathrm{h}^{-1}\right)$, and hourly observed precipitation type (dots) indicating snow (black), ice pellets (blue), wet snow (red), freezing rain (pink), or rain (green) at (a) YQB, (b) YUL, and (c) YOW. Station locations are indicated in Fig. 1. 
(a) P3_MOD-P3_ORIG Freezing rain

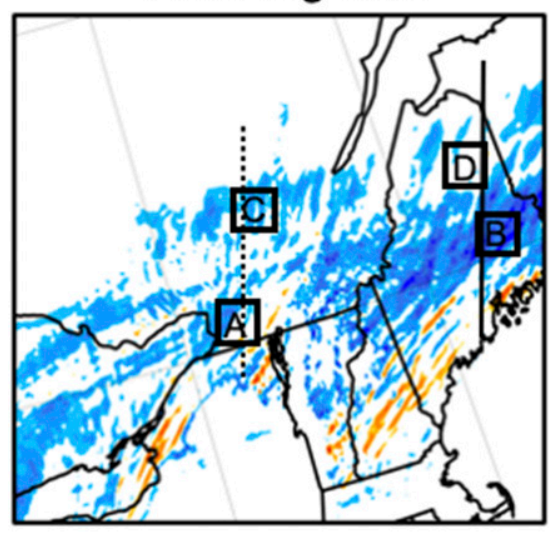

(c) P3_MOD

Wet snow acc.

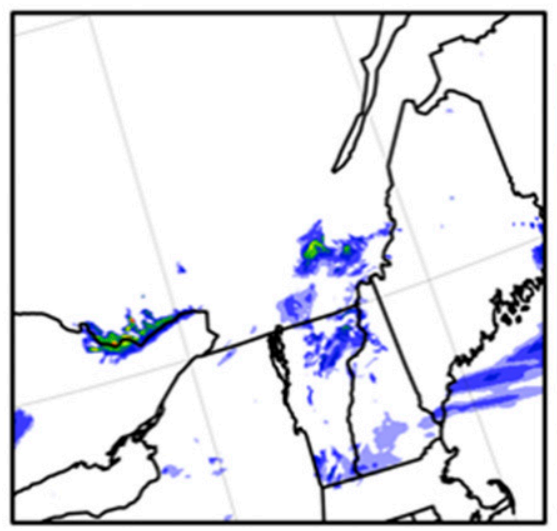

(b) P3_MOD-P3_ORIG Total solid
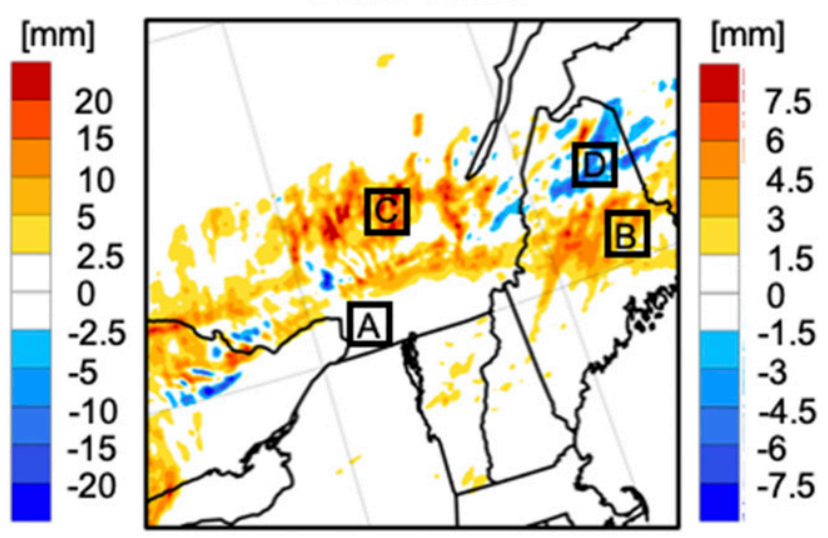

(d) P3_MOD

Ice pellets acc.
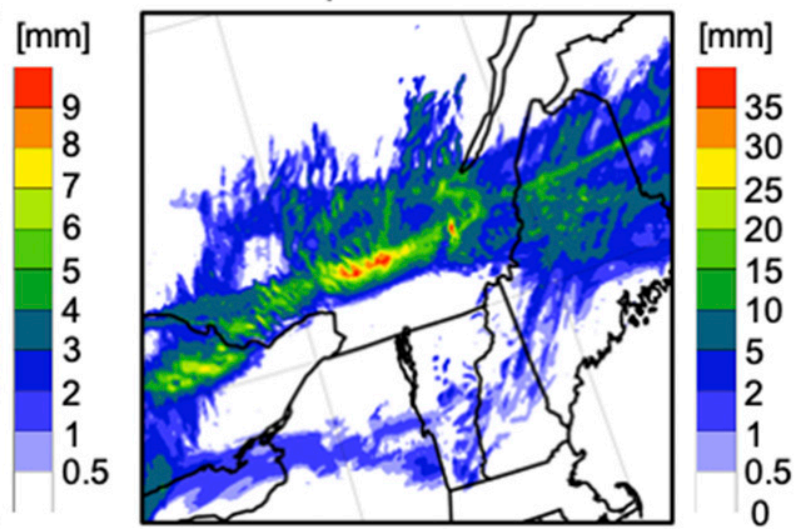

FIG. 7. (a),(b) P3_MOD-P3_ORIG accumulated precipitation (mm) from 0600 UTC 4 Jan to 0600 UTC 10 Jan 1998 of (a) freezing rain and (b) total solid. (c),(d) P3_MOD accumulated precipitation (mm) from 0600 UTC 4 Jan to 0600 UTC 10 Jan 1998 of (c) wet snow and (d) ice pellets. Also shown are the locations of the four subregions A, B, C, and D [squares in (a) and (b)] and the two cross sections for Figs. 11-13 [dotted and solid lines in (a)].

determine if there is an overestimation (or underestimation) by comparing with Lecompte et al. (1998) since the $0-20 \mathrm{~mm}$ bin of freezing rain accumulation is not shown in their figure. The subregion-averaged ice pellet accumulations in P3_MOD are 4.2, 7.7, and $5.9 \mathrm{~mm}$ for subregions $\mathrm{B}, \mathrm{C}$, and $\mathrm{D}$, respectively. All subregions except $\mathrm{D}$ are associated with a decrease of freezing rain accumulation and an increase of total solid accumulation in P3_MOD compared to P3_ORIG.

\section{b. Temporal evolution of precipitation rate and the $0^{\circ} \mathrm{C}$ isotherm}

The temporal evolution of the subregion-averaged $0^{\circ} \mathrm{C}$ isotherm height, freezing rain and ice pellets rates, and accumulated precipitation difference between P3_MOD and P3_ORIG are shown in Fig. 9. For subregions A and $\mathrm{B}$, the durations of the two icing periods are similar (listed in Table 4). Ice pellets (Fig. 9c) occur in P3_MOD at the beginning of each icing period and at the end of the second one in the subregion B associated with a lower freezing rain rate in P3_MOD compared to P3_ORIG. Major differences between P3_MOD and P3_ORIG are evident during the second half of the first icing period for subregions $\mathrm{A}$ and $\mathrm{B}$ and overall during the second icing period in all subregions (Fig. 9d). This is when the precipitation rate is higher, and the melting layer is deep (between 1500 and $2000 \mathrm{~m}$ ) enough to melt ice completely producing freezing rain for subregions $\mathrm{A}$ and $\mathrm{B}$. The second icing period is similar in subregions $\mathrm{C}$ and $\mathrm{D}$ but shorter in subregion C (Figs. 9a,b). Note that subregion D has no 
(a) Total

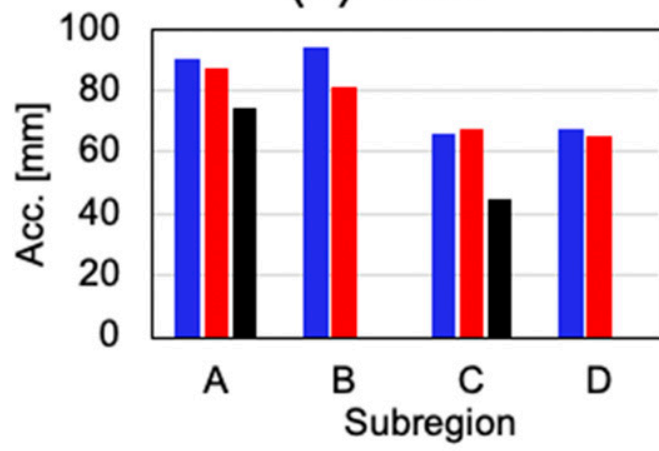

(c) Total solid

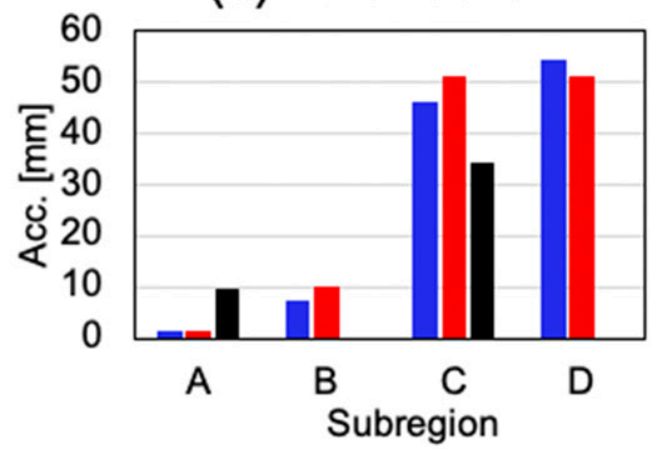

(b) Total liquid

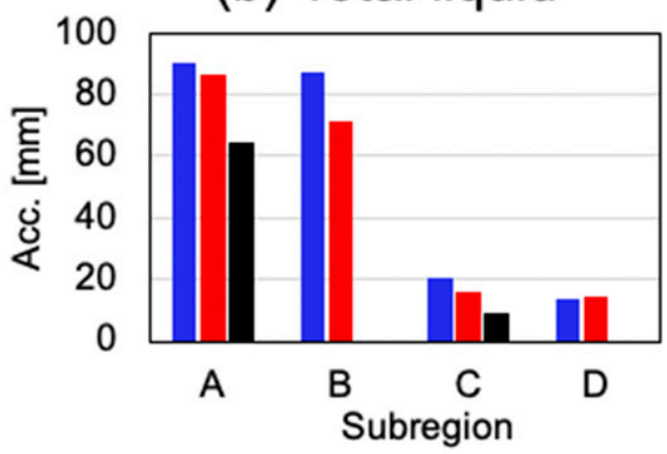

(d) Freezing rain

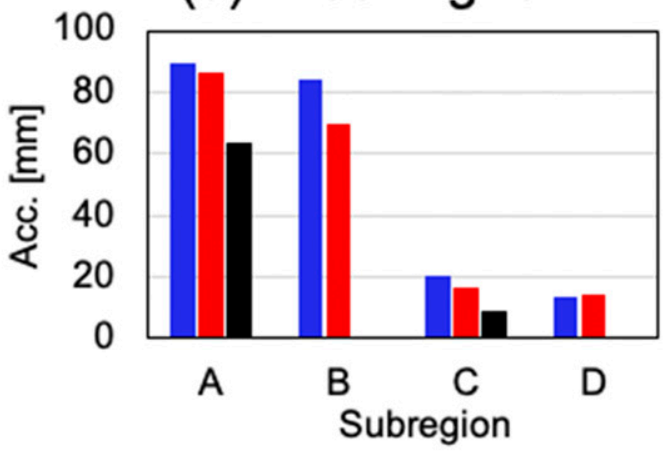

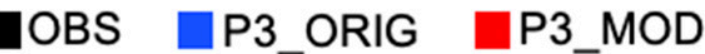

FIG. 8. Observed (black, when available), P3_ORIG (blue), and P3_MOD (red) accumulated precipitation (mm) averaged over the subregions A, B, C, and D from 0600 UTC 4 Jan to 0600 UTC 10 Jan 1998 of (a) total precipitation, (b) total liquid precipitation, (c) total solid precipitation, and (d) freezing rain. Locations of the four subregions are shown in Figs. $7 \mathrm{a}$ and $7 \mathrm{~b}$.

first icing period at all (Table 4 and Figs. 9a,b). Most of the changes in accumulated freezing rain between P3_MOD and P3_ORIG in subregions C and D occur when ice pellets are produced in P3_MOD. This is when the depth and the maximum temperature of the melting layer are $<1000 \mathrm{~m}$ and $<2^{\circ} \mathrm{C}$, respectively (Zerr 1997). For subregion D, a small increase of accumulated freezing rain occurs at the beginning of the second icing period (from 1200 UTC 8 January to 0000 UTC 9 January). Overall, the largest differences between P3_MOD and P3_ORIG in precipitation rates are during the second icing period and when the surface precipitation rate is highest. In addition to microphysical differences, this difference could be due to a slightly deeper and warmer melting layer in P3_MOD compared to P3_ORIG small (blue line in Fig. 9a). Differences in the thermodynamic profiles between the two simulations are, however, small. For instance, the upper boundary of the melting layer (based on the $0^{\circ} \mathrm{C}$ level) in P3_MOD is lower by about
$15 \mathrm{~m}$ compared to P3_ORIG, and the maximum temperature of the melting layer is warmer by about $0.15^{\circ} \mathrm{C}$ in Fig. 9.

\section{c. Vertical structures of particle size distributions}

The vertical structure of the particle size distribution (PSD) is investigated because it is impacted by the melting and refreezing rates of particles (Thériault et al. 2010). This also illustrates the behavior of mean particle diameters for both ice and rain (freezing rain). We focus on the second icing period because larger differences between P3_MOD and P3_ORIG occur than compared to the first period (see Fig. 9). Differences between the two icing periods will also be discussed in this section with regard to the mean ice size distribution above the melting layer.

Figure 10a shows time-averaged vertical profiles of temperature during the second icing period (see Table 4) averaged over the four subregions A-D for both simulations. For subregions A and B, ice has melted completely 

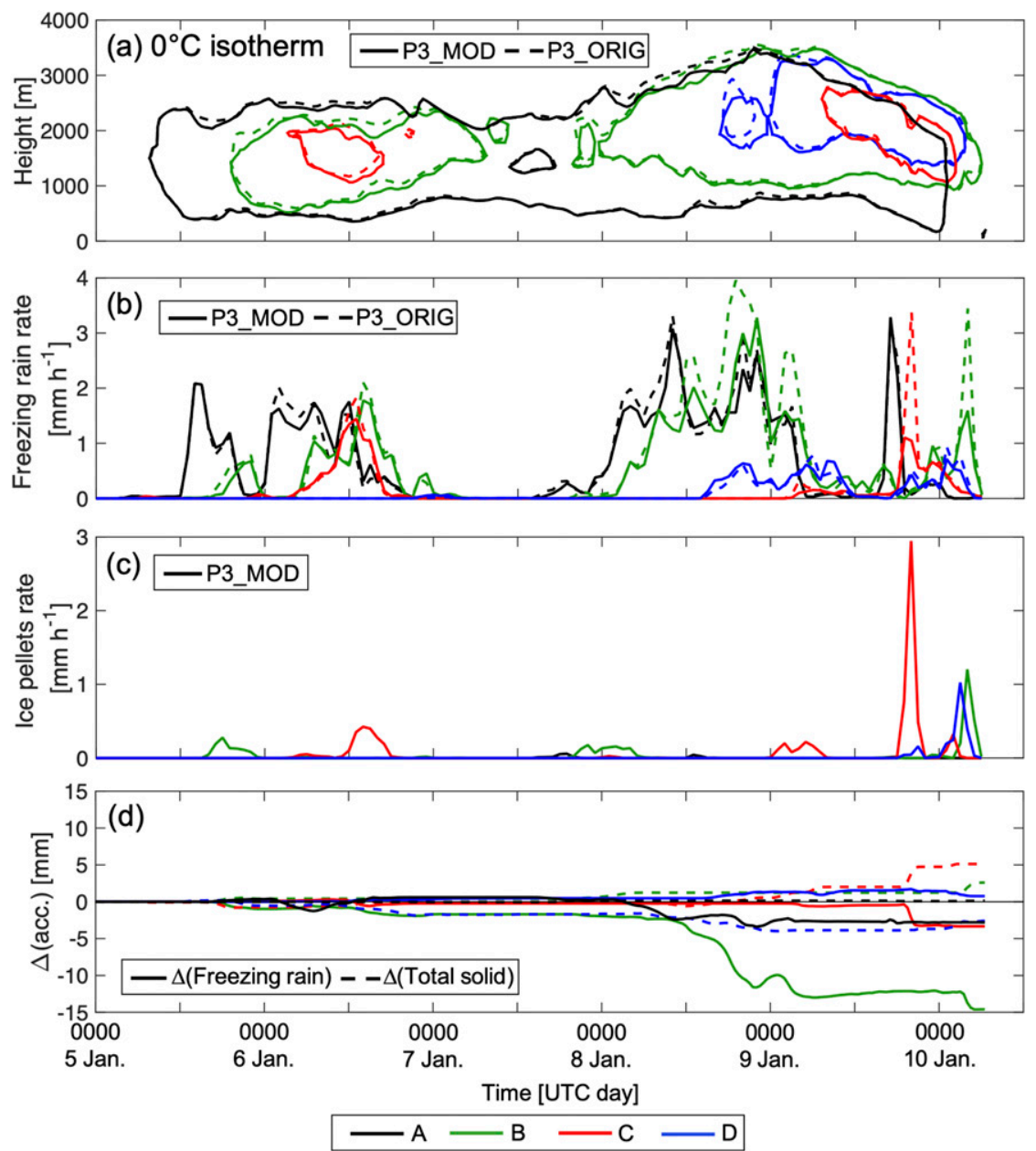

FIG. 9. Temporal evolution of (a) P3_MOD (solid) and P3_ORIG (dashed) $0^{\circ} \mathrm{C}$ isotherm, (b) P3_MOD (solid) and P3_ORIG (dashed) freezing rain rate $\left(\mathrm{mm} \mathrm{h}^{-1}\right)$, (c) P3_MOD ice pellet precipitation rate $\left(\mathrm{mm} \mathrm{h}^{-1}\right)$, and (d) P3_MOD-P3_ORIG cumulative difference over the time period $[\Delta(\mathrm{acc}),. \mathrm{mm}]$ freezing rain (solid) and total solid precipitation (dashed). Results are averaged over the four subregions A (black), B (green), C (red), and D (blue) shown in Figs. $7 \mathrm{a}$ and $7 \mathrm{~b}$.

producing freezing rain at the surface because the melting layer is very deep. Subregions C and D are associated with deeper and colder refreezing layers compared to subregions A and B. In general, the vertical temperature profiles produced by P3_MOD and P3_ORIG are similar, with some small differences. P3_MOD is slightly colder above the height of the maximum temperature of the melting layer whereas it is slightly warmer below it.

The mean PSDs at different heights (i.e., top of the melting layer, at the bottom of the melting layer, and at the surface) are shown in Figs. 10b-f. Note that only ice size distributions in subregions $\mathrm{C}$ and $\mathrm{D}$ are shown in Fig. 10d as the ice melted completely in subregions A

TABLE 4. Icing time periods for each subregion shown in Figs. 7a and 7b.

\begin{tabular}{ccc}
\hline \hline Subregion & First icing period & Second icing period \\
\hline A & 0000 UTC 5 Jan-1200 UTC 7 Jan & 2000 UTC 7 Jan-0600 UTC 10 Jan \\
B & 1800 UTC 5 Jan-1200 UTC 7 Jan & 2000 UTC 7 Jan-0600 UTC 10 Jan \\
C & 0300 UTC 6 Jan-1800 UTC 6 Jan & 0000 UTC 9 Jan-0600 UTC 10 Jan \\
D & - & 1200 UTC 8 Jan-0600 UTC 10 Jan \\
\hline
\end{tabular}



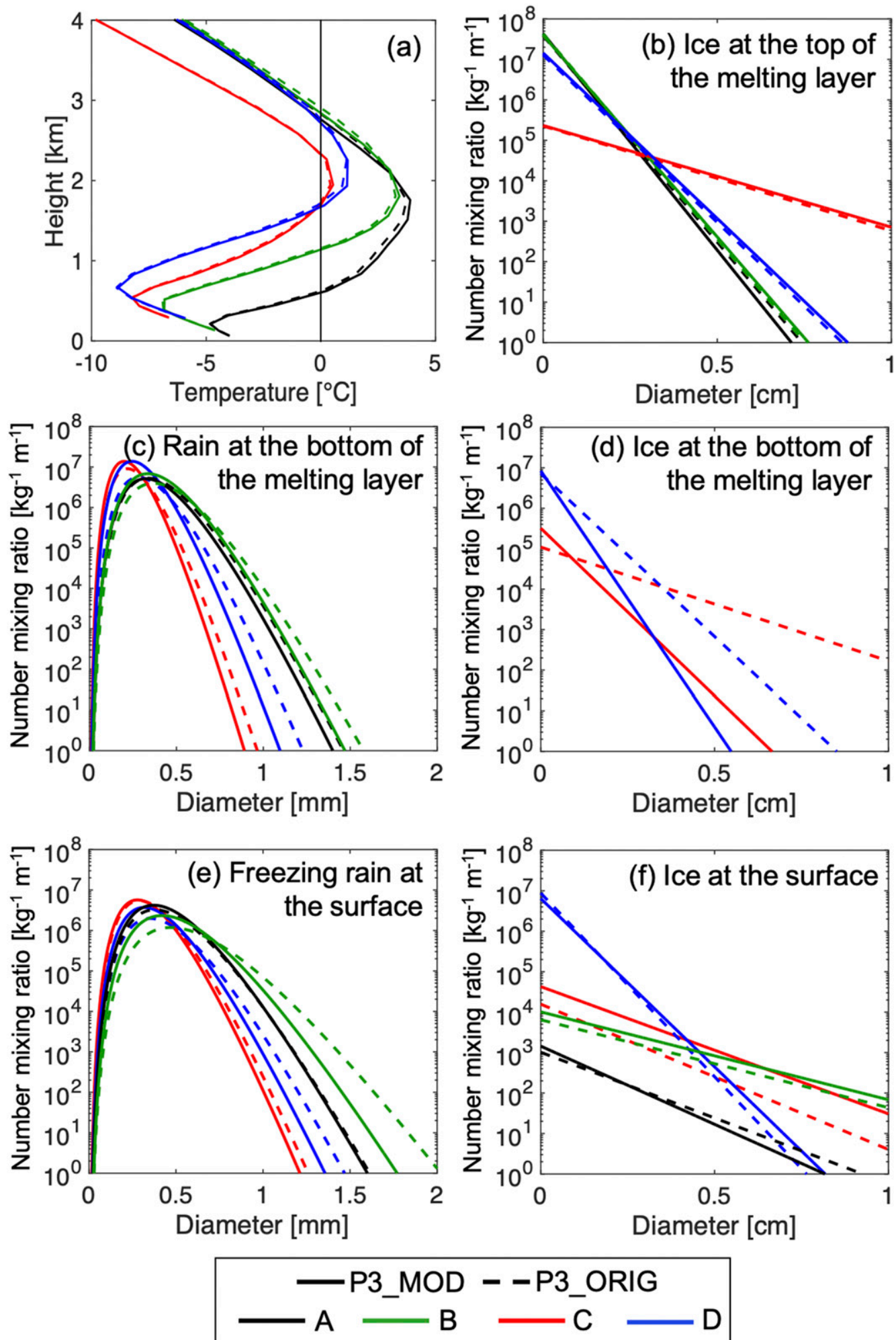

FIG. 10. (a) Vertical profiles of temperature $\left({ }^{\circ} \mathrm{C}\right)$ and (b)-(f) particle size distributions $\left(\mathrm{kg}^{-1} \mathrm{~m}^{-1}\right)$ for (b) ice at temperature near $-1.5^{\circ} \mathrm{C}$ just above the melting layer, (c) rain at the bottom of the melting layer, (d) ice at the bottom of the melting layer, (e) freezing rain at the surface, and (f) ice at the surface using P3_MOD (solid) and P3_ORIG (dashed). Results are temporally averaged over the second icing period (see Table 4) and spatially averaged over subregions A (black), B (green), C (red), and D (blue) shown in Figs. 7a and 7b. 
and $\mathrm{B}$. There is ice at the surface in subregions $\mathrm{A}$ and B (Fig. 10f) produced by immersion freezing of rain and cloud droplets allowed at temperatures $<-4^{\circ} \mathrm{C}$ in the refreezing layer in both P3_MOD and P3_ORIG. However, this ice is very low in number $\left(N_{i, \text { tot }}<20 \mathrm{~kg}^{-1}\right)$ and mass $\left(q_{i, \text { tot }}<0.0001 \mathrm{~g} \mathrm{~kg}^{-1}\right)$ mixing ratios and only accumulated in trace amounts $(<0.1 \mathrm{~mm})$ over the entire length of the simulation.

We highlight three particular results. First, all ice distributions (Figs. 10b,d,f) are inverse-exponential $(\mu=0)$. Note that the shape parameter $\mu$ for ice in P3 is a function of $\lambda$ [Eq. (2) and hence inversely related to mean ice particle size]. The value of $\mu$ is generally $>0$ when the rime mass fraction is high (e.g., $F_{i, \text { rim }}>0.9$ ) or when the number mixing ratio is high (e.g., $N_{i, \text { tot }}>1$.e + $\left.5 \mathrm{~kg}^{-1}\right)$, but these conditions are not met for the results shown in Fig. 10 and $\mu=0$. At the top of the melting layer (Fig. 10b), the intercept parameters are higher, and the rime mass fractions are lower in P3_MOD compared to P3_ORIG in subregions A, B, and D. The ice mean mass-weighted diameter at the top of the melting layer is similar between P3_MOD and P3_ORIG (near $\sim 0.2 \mathrm{~cm}$ ), but with slightly smaller values for P3_MOD in all subregions, except in $\mathrm{C}$ where it is slightly larger. A larger mean mass-weighted diameter of ice aloft is obtained in subregion B during the second icing period with mean value of $\sim 0.24 \mathrm{~cm}$ for both P3_MOD and P3_ORIG. This corresponds to higher precipitation rates (Fig. 9). Second, at the bottom of the melting layer, which also corresponds to the top of the refreezing layer, the ice distributions in P3_MOD are shifted toward smaller mean diameters compared with those above the melting layer (cf. Figs. 10b,d). In contrast, P3_ORIG produces similar ice distributions at these two levels. This occurs because the mean ice mass-weighted diameter decreases and the mean mass-weighted fall speed increases with partial melting of ice in P3_MOD, whereas the mean ice diameter is constant during melting in P3_ORIG (C19). Third, the mean ice diameter in P3_MOD increases while falling through the refreezing layer while it remains fairly constant in P3_ORIG (Figs. 10d,f). This increase in P3_MOD is mainly due to the refreezing process, which transfers mass from $q_{i \text {,iq }}$ to $q_{i, \text { rim }}$, thus reducing the liquid mass fraction gradually. Higher mean ice diameters in P3_MOD lead to higher precipitation rates and accumulated solid precipitation, particularly in subregion C (Fig. 8c).

Differences in the ice size distribution aloft between the first (not shown) and second icing periods explain the difference in the surface precipitation rate. The PSD slope and intercept parameters above the melting layer are smaller during the second icing period, implying larger mean particle sizes. PSDs during the second icing period are also generally characterized by higher $q_{i, \text { tot }}$, smaller $N_{i, \text { tot }}$, higher $F_{i, \text { rim }}$, and higher $\rho_{i, \text { rim }}$.

The rain and freezing rain drop size distributions (Figs. 10c,e) produced by P3_MOD have higher slope and intercept parameters compared to P3_ORIG. The mean mass-weighted diameter of rain and freezing rain $\left(D_{r}\right)$ is always smaller in P3_MOD compared to P3_ORIG in all four subregions. The maximum decrease of P3_MOD mean mass-weighted diameter of freezing rain at the surface compared to P3_ORIG is $\sim 0.2 \mathrm{~mm}$ in subregion B. This difference is mainly associated with the differences in the representation of the melting process. The production of smaller raindrops diameters is associated with a lower precipitation rate in P3_MOD than P3_ORIG. This will be discussed further in the following section.

\section{d. Microphysical properties of precipitation aloft}

An analysis of microphysical variables along two cross sections (dotted and solid lines in Fig. 7a) is shown in Figs. 11-13. The variables are time averaged over the second icing period. This time period was chosen because large differences are produced between P3_MOD and P3_ORIG, particularly in subregion B. One cross section extends from subregion A to C (Fig. 11) and the other one is from subregion B to D (Figs. 12 and 13). Note that the predicted mass mixing ratios have been multiplied by air density and hence are expressed as mass contents in $\mathrm{g} \mathrm{m}^{-3}$ in Figs. 11-13.

Figures 11 and 12 show hydrometeor water contents as well as rime and liquid mass fractions of ice from both simulations and their differences (P3_MOD-P3_ORIG). The ice entering the melting layer in subregions A (Figs. 11a,b) and B (Figs. 12a,b) melts completely to produce freezing rain at the surface. No melting layer aloft is present over subregion $\mathrm{C}$ leading to mainly snow during that time period (Figs. 11a,b). A mixture of freezing rain and ice pellets occurs in subregion $\mathrm{D}$ (Figs. 12a,b,i,j) and between subregions $\mathrm{A}$ and $\mathrm{C}$ (Figs. 11a,b and Figs. 11i,j). Ice entering the melting layer aloft is slightly rimed (rime mass fraction $\sim 0.15$ ) south of subregion C (Figs. 11d,e: $\sim 0-125 \mathrm{~km}$ ) and in subregion B (Figs. 12d,e: $\sim 0-120 \mathrm{~km}$ ). The total ice mass mixing ratio above the melting layer is greater and more rimed over subregion B compared to D (Figs. 12a,b,d,e). For both cross sections, $q_{\text {rain }}$ (Figs. 11i,j and Figs. 12i,j) is higher in the melting layer where $q_{i, \text { tot }}$ above the melting layer is higher $\left(\sim 0.25-0.3 \mathrm{~g} \mathrm{~kg}^{-1}\right)$. Cloud water (Figs. 111,m and 121,m) is generally formed through supersaturated conditions produced by diabatic cooling associated with melting near the top of the melting layer. 
P3_ORIG
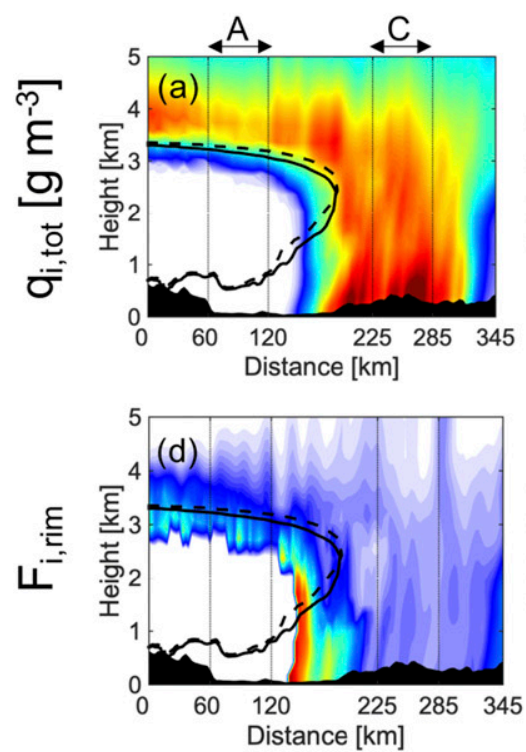

$\stackrel{\underline{\underline{\sigma}}}{\text { ए }^{-}}$
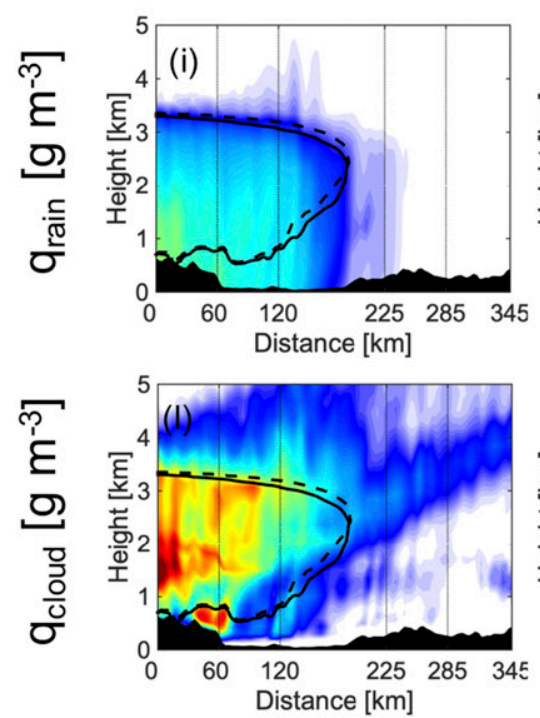

P3_MOD
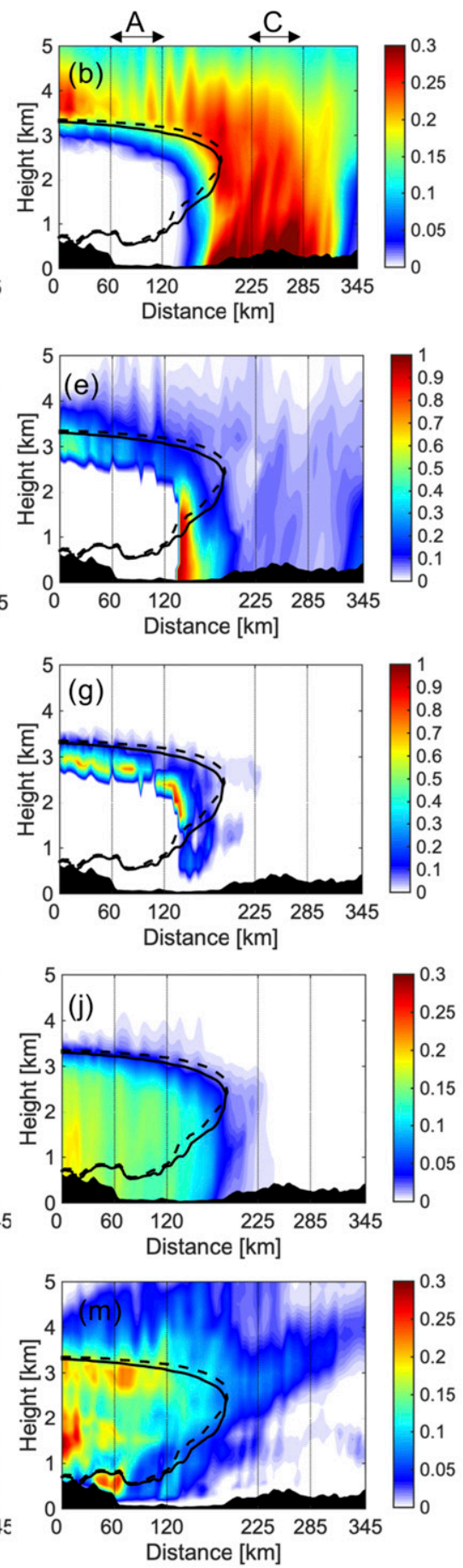

P3_MOD-P3_ORIG
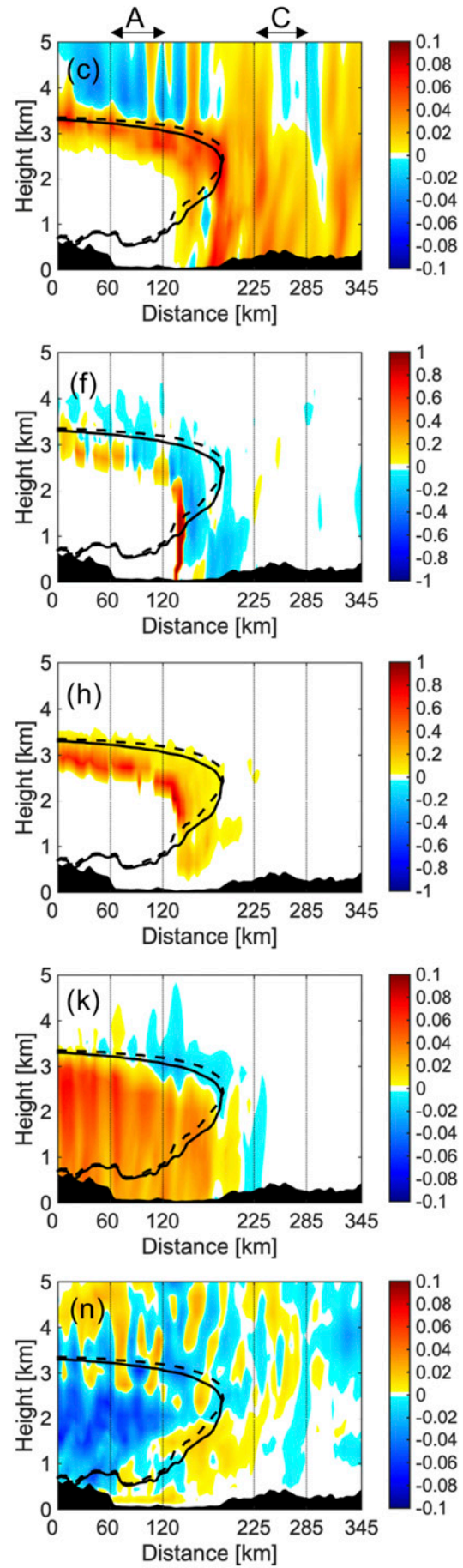

\section{----P3_ORIG $0^{\circ} \mathrm{C}$-isotherm}

P3_MOD $0{ }^{\circ} \mathrm{C}$-isotherm

FIG. 11. P3_ORIG (left), P3_MOD (center), and P3_MOD-P3_ORIG (right) simulated vertical cross sections between subregions A and $\mathrm{C}$ (dotted line in Fig. 7a) of (a)-(c) total ice mass mixing ratio $\left(q_{i, \text { tot }} ; \mathrm{g} \mathrm{m}^{-3}\right)$, (d)-(f) rime mass fraction of ice $\left(F_{i, \text { rim }}\right)$, (g), (h) liquid mass fraction $\left(F_{i, \text { liq }}\right),(\mathrm{i})-(\mathrm{k})$ rain mass mixing ratio $\left(q_{\text {rain }} ; \mathrm{g} \mathrm{m}^{-3}\right)$, and $(\mathrm{l})-(\mathrm{n})$ cloud mass mixing ratio $\left(q_{\text {cloud }} ; \mathrm{g} \mathrm{m}^{-3}\right)$. Results are time averaged from 0600 UTC 8 Jan to 0600 UTC 9 Jan 1998. Also shown are the $0^{\circ} \mathrm{C}$ isotherms in black lines for P3_ORIG (dashed) and P3_MOD (solid). 
P3_ORIG
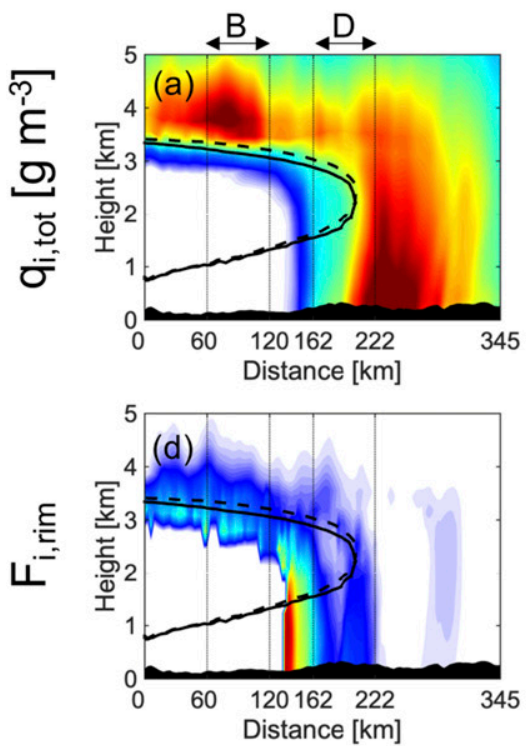

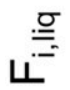
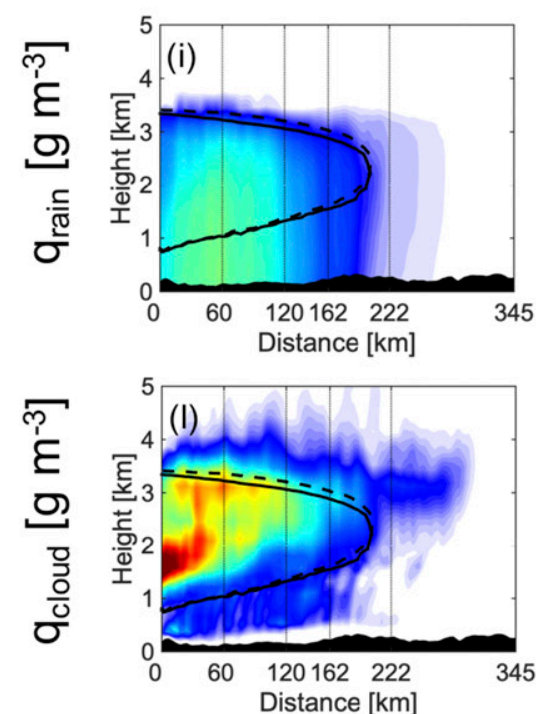

P3 MOD
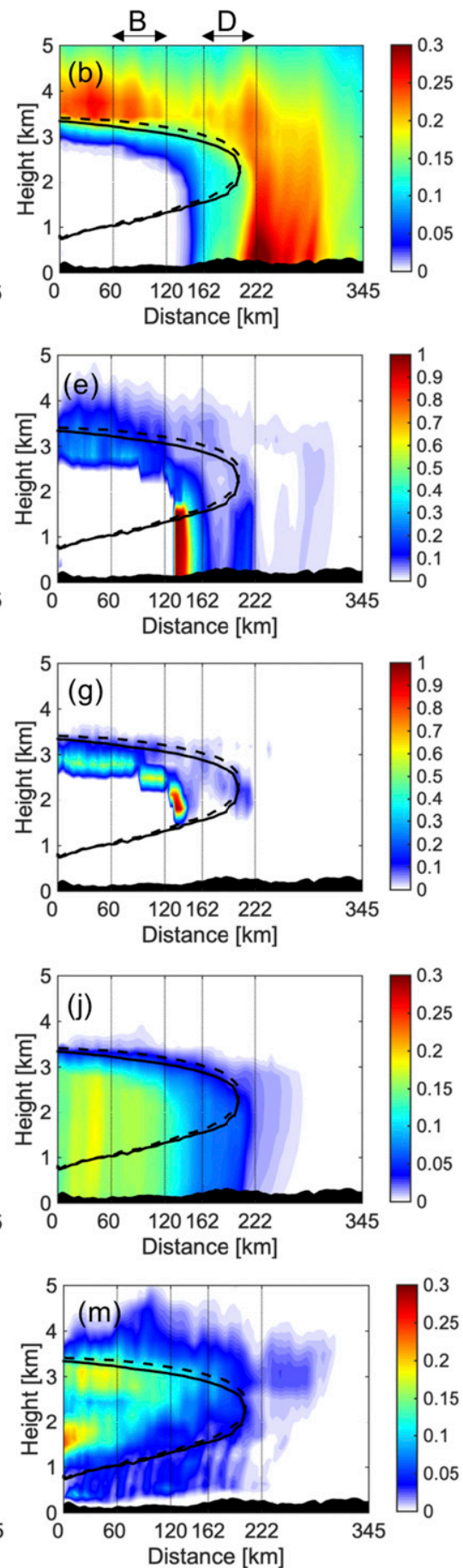

P3_MOD-P3_ORIG
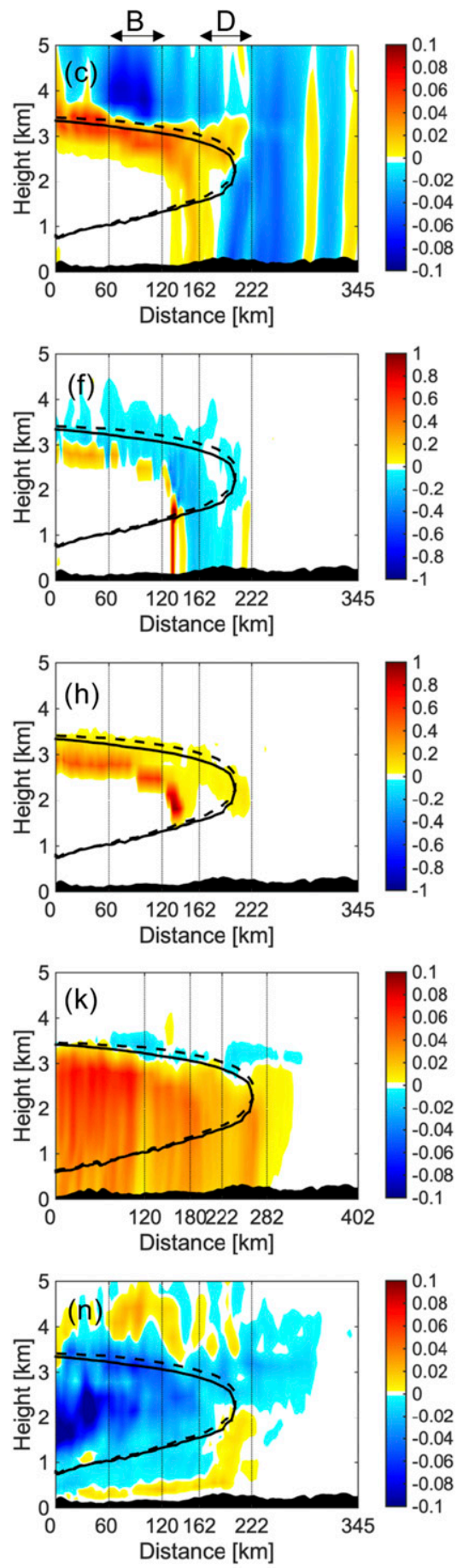

\section{----P3_ORIG $0^{\circ} \mathrm{C}$-isotherm -P3_MOD $0^{\circ} \mathrm{C}$-isotherm}

FIG. 12. As in Fig. 11, but for the cross section between subregions B and D (solid line in Fig. 7a). 

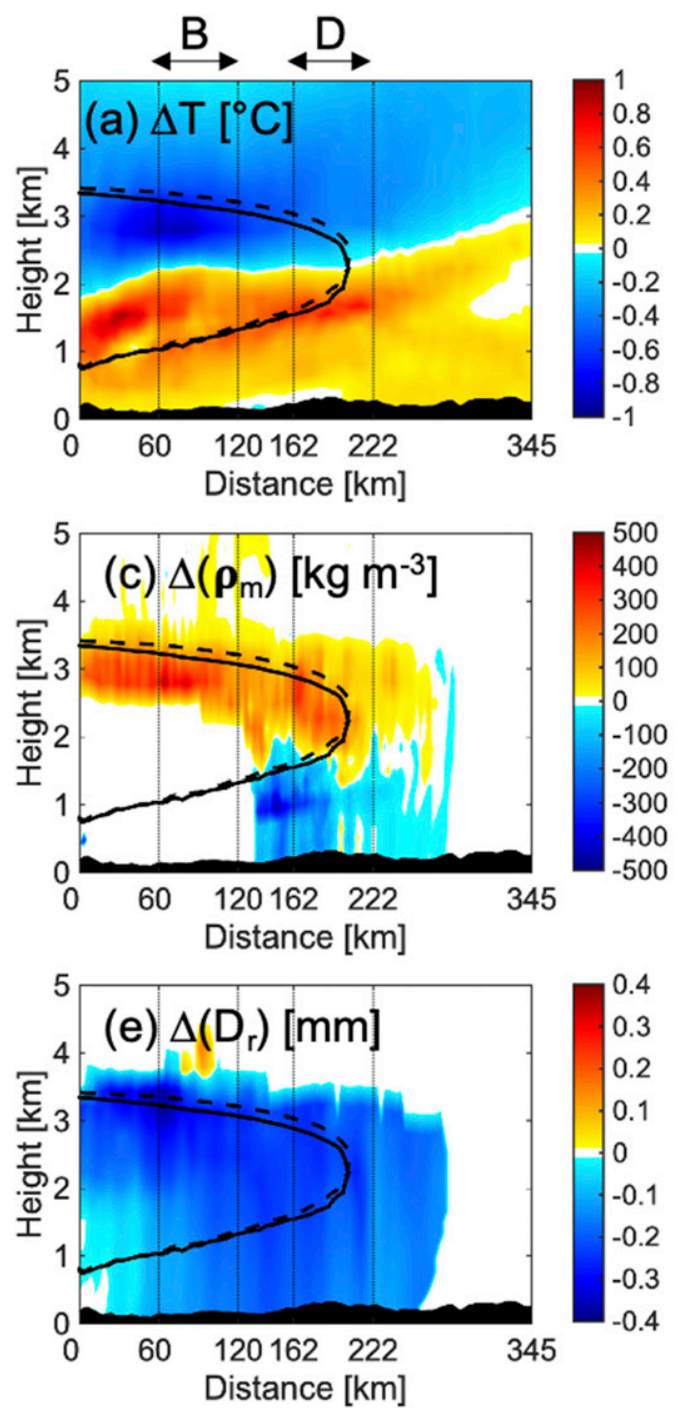

P3_ORIG $0^{\circ} \mathrm{C}$-isotherm
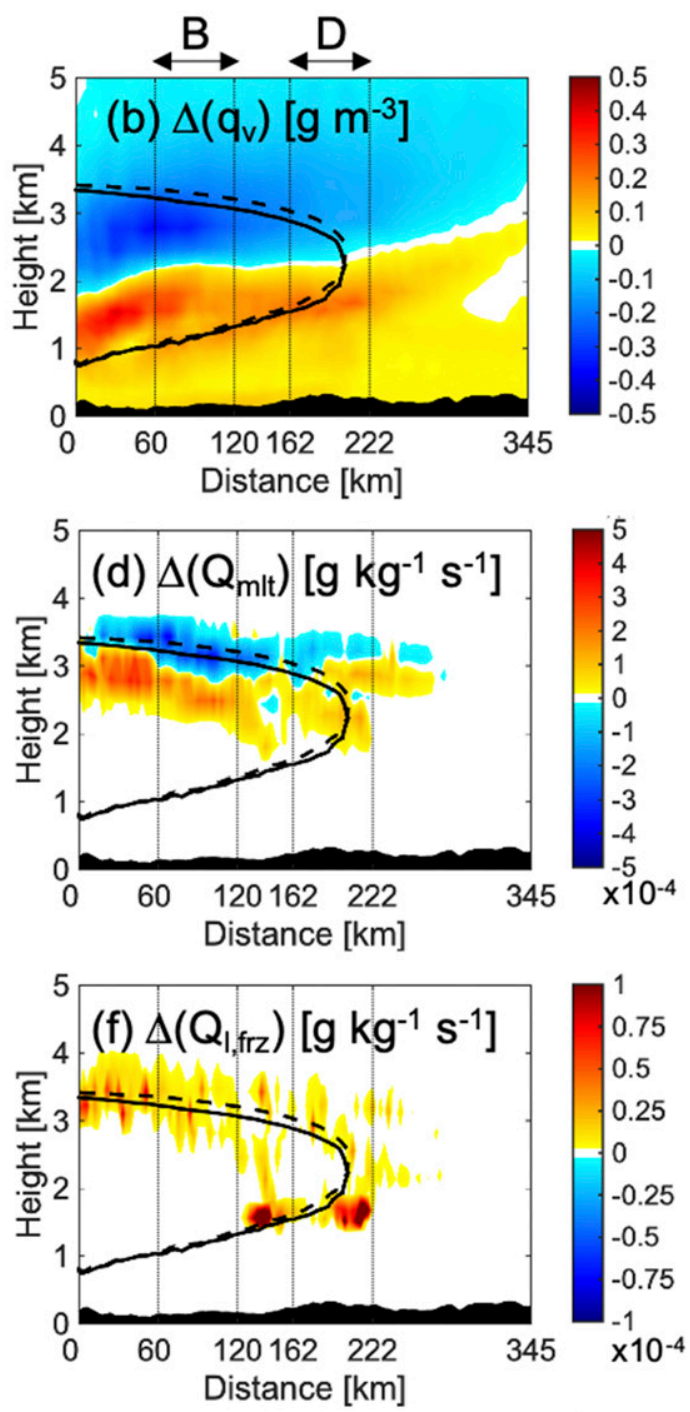

P3_MOD $0^{\circ} \mathrm{C}$-isotherm

FIG. 13. Vertical cross sections between subregions B and D (solid line in Fig. 7c) of differences (P3_MODP3_ORIG) in (a) temperature $\left(\Delta T,{ }^{\circ} \mathrm{C}\right),\left(\right.$ b) water vapor mixing ratio $\left(\Delta q_{v}, \mathrm{~g} \mathrm{~m}^{-3}\right),(\mathrm{c})$ mean mass-weighted density of ice $\left(\Delta \rho_{m}, \mathrm{~kg} \mathrm{~m}^{-3}\right)$, (d) total melting process rate $\left(\Delta Q_{\mathrm{mlt}}, \mathrm{g} \mathrm{kg}^{-1} \mathrm{~s}^{-1}\right)$, (e) mean mass-weighted diameter of rain/freezing rain $\left.\left(\Delta D_{r}\right), \mathrm{mm}\right)$, and (f) refreezing process rate $\left(\Delta Q_{l, \mathrm{frz}}, \mathrm{g} \mathrm{kg}^{-1} \mathrm{~s}^{-1}\right)$. Results are time averaged from 0600 UTC 8 Jan to 0600 UTC 9 Jan 1998 . Also shown are the $0^{\circ} \mathrm{C}$ isotherms in black lines for P3_MOD (solid) and P3_ORIG (dashed).

The main differences between P3_MOD and P3_ORIG are summarized as follows. $q_{i, \text { tot }}$ (Figs. $11 \mathrm{c}$ and $12 \mathrm{c}$ ) above the melting layer is smaller in P3_MOD compared to P3_ORIG, particularly over subregion B (Fig. 12c). The rime mass fraction is generally smaller in $\mathrm{P} 3$ _MOD compared to P3_ORIG. However, $F_{i, \text { rim }}$ is larger in P3_MOD in some regions of melting (e.g., Figs. $11 \mathrm{f}$ and $12 \mathrm{f}$ near 0-60 km) and, also, in the refreezing layer (Figs. 11f and $12 \mathrm{f}$ near $130 \mathrm{~km}$ ). The rain mass mixing ratio is greater everywhere in P3_MOD compared to P3_ORIG for both cross sections (Figs. $11 \mathrm{k}$ and $12 \mathrm{k}$ ). Last, $q_{\text {cloud }}$ (Figs. 11n and 12n) is generally smaller in P3_MOD compared to P3_ORIG within the melting layer.

Because P3_MOD and P3_ORIG used the same configuration and setup of WRF, the changes between the two simulations illustrated in Figs. 11 and 12 must be associated with the different microphysical formulations owing to prediction of $F_{i, \text { liq }}$ in P3_MOD. Figure 13 shows the differences between P3_MOD and P3_ORIG in vertical structures of temperature (Fig. 13a), water vapor 
mixing ratio (Fig. 13b), and various microphysical properties (Figs. 13c-f) for the cross section between subregions $\mathrm{B}$ and $\mathrm{D}$. Note that the melting and refreezing processes are only computed in the model when the temperature is $<0^{\circ} \mathrm{C}$ (refreezing) or $>0^{\circ} \mathrm{C}$ (melting), but the process rates and temperatures shown in Figs. 13d and $13 \mathrm{f}$ are time averaged; thus, nonzero melting and refreezing rates are seen beyond these temperature limits in the figures. These results do not reflect all the simulated times, however, some general features explaining differences in the behaviors of P3_MOD and P3_ORIG are discussed below.

The prediction of $F_{i, \text { liq }}$ in P3_MOD allows different representations of hydrometeor properties while they undergo melting in contrast to P3_ORIG. For instance, P3_MOD allows for a decrease in the diameter and an increase in both fall speed and density during melting, while these behaviors are not represented in P3_ORIG (C19). The increase in density (shown in Fig. 13c) and hence fall speed during melting induces a deeper melting depth in P3_MOD compared to P3_ORIG (Fig. 13d). This tends to produce more solid precipitation such as ice pellets instead of freezing rain and wet snow instead of rain in P3_MOD due to partial melting associated with shorter residence time of particles in the melting layer. Also, the partial melting explicitly treated in P3_MOD, combined with shedding of accumulated liquid water when the melting ice is partially or fully rimed (neglected in P3_ORIG), produces higher melting rates leading to greater rain mass (Fig. 12k) and number mixing ratios (not shown). In particular, the change in rain number mixing ratio from melting is scaled by a factor of 0.2 in P3_ORIG to account implicitly for evaporation of melting ice (see Appendix), while this is not done in P3_MOD. Thus, the melting process in $\mathrm{P} 3$ _MOD affects the proportions of rain versus ice produced in the melting layer and induces a higher cooling rate from melting near the top of the melting layer compared to P3_ORIG (Fig. 13a). These differences are generally larger when the rime mass fraction aloft is greater associated with higher surface precipitation rates $\left(>1.5-2 \mathrm{~mm} \mathrm{~h}^{-1}\right)$. These differences also lead to a smaller mass-weighted mean diameter of rain and freezing rain in P3_MOD compared to P3_ORIG (Fig. 13e). This, in turn, reduces the freezing rain rate, contributing to smaller freezing rate accumulations at the surface in P3_MOD compared to P3_ORIG.

A sensitivity test has been made to assess the impacts on the differences between P3_MOD and P3_ORIG of the P3_ORIG's melting scaling factor of 0.2 for the change in $N_{\text {rain }}$ due to melting. The third simulation is identical to P3_ORIG but uses a melting scaling factor of 1 (hereafter called P3_ORIG1). By increasing the number mixing ratio of melting transferred to rain in
P3_ORIG1, the magnitude of the decrease in the mean mass-weighted diameter of rain of P3_MOD compared to P3_ORIG1 during melting is smaller (not shown) than the one presented in Fig. 13e. However, results of the differences in accumulated freezing rain and total solid show that the differences between P3_MOD and both P3_ORIG simulations are larger than those between P3_ORIG and P3_ORIG1 (Fig. 14). Overall, the differences between P3_MOD and both P3_ORIG are systematic and show an increase in total solid and a decrease in freezing rain accumulations.

Other processes within the melting layer include cloud water accretion by rain and condensation (not shown). The larger $q_{\text {rain }}$ in P3_MOD increases the cloud water accretion rate, which results in lower $q_{\text {cloud }}$ in the melting layer (Figs. 11n and 12n). The condensation of $q_{i, \text { liq }}$ acts as a source term for water vapor in P3_MOD whereas it is neglected above $0^{\circ} \mathrm{C}$ in P3_ORIG, thus competing for available water vapor with $q_{\text {cloud }}$ and $q_{\text {rain }}$. Condensation rates, in particular those for $q_{\text {cloud }}$, mostly depend on the thermodynamic and dynamics conditions (e.g., vertical velocity and temperature). However, for rain and P3_MOD's mixed-phase ice, the rates are more sensitive to the microphysical characteristics including mass content and number concentration. This is because the phase relaxation time for cloud condensation is usually small, of order $1-10 \mathrm{~s}$, regardless of the microphysical characteristics, whereas the phase relaxation time scale for rain and mixed-phase particles is usually much longer and is more sensitive to the microphysical properties. It is found that the rain condensation rate in P3_MOD associated with Figs. 11 and 12 is slightly greater compared to P3_ORIG, contributing to the higher air temperature in the melting layer.

Last, in the refreezing layer, the refreezing of partially melted ice (Fig. 13f) in P3_MOD increases the air temperature near the top of the refreezing layer (Fig. 13a) and changes the ice properties gradually, such as the mean mass-weighted diameter, compared to P3_ORIG. For instance, refreezing of partially melted ice increases the mean diameter of ice, which increases the solid precipitation rate and accumulation in region with ice pellet accumulation in P3_MOD in contrast to P3_ORIG. The differences between P3_MOD and P3_ORIG are greater when conditions of wet growth are met above the melting layer. It should be noted that wet growth (not shown) and refreezing rates near the upper $0^{\circ} \mathrm{C}$ height of the melting layer are small. In general, wet growth is associated with hail growth in a strong updraft. However, wet growth in P3, parameterized following Musil (1970), still can occur in nonhail conditions and this is the case here. In P3_ORIG, cloud droplets and raindrops collected during wet growth are directly transferred to $q_{i, \text { rim }}$ with some 


\section{P3 MOD-P3_ORIG1}
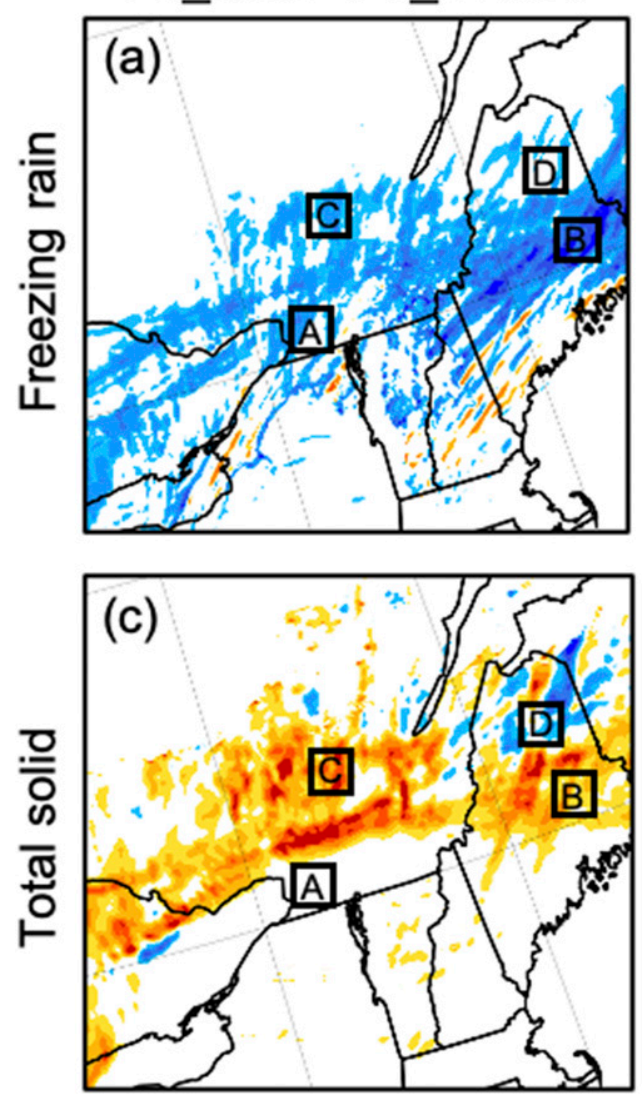

\section{P3_ORIG-P3_ORIG1}
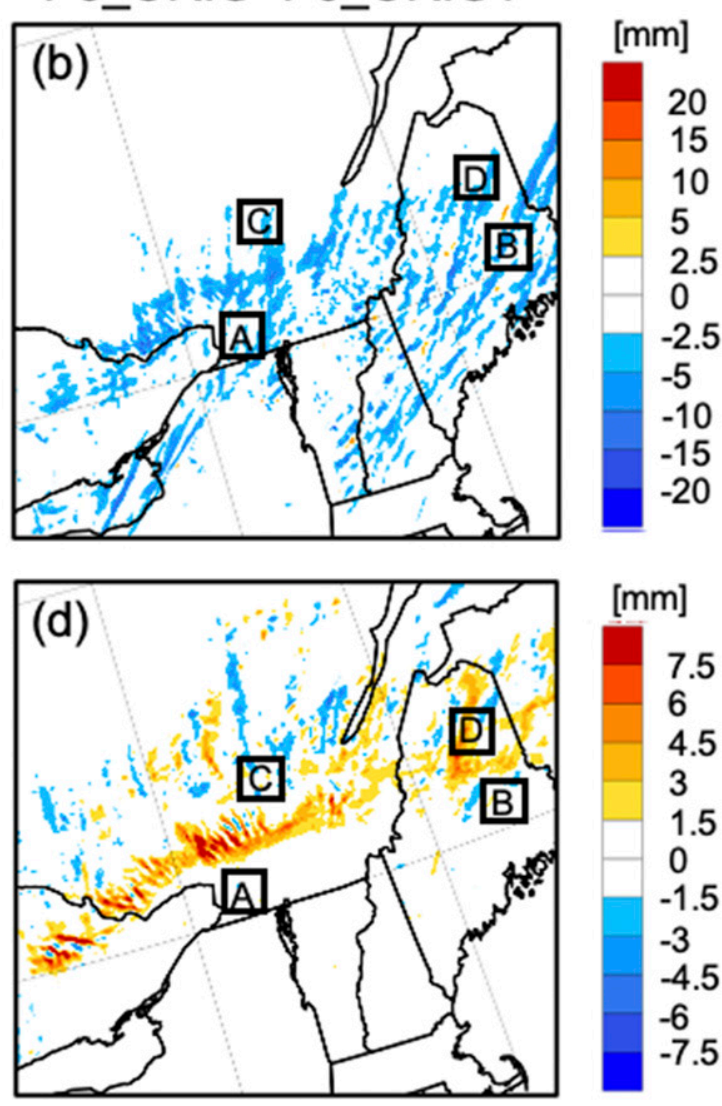

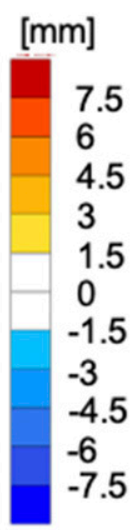

FIG. 14. (a),(c) P3_MOD-P3_ORIG1 and (b),(d) P3_ORIG-P3_ORIG1 accumulated precipitation (mm) from 0600 UTC 4 Jan to 0600 UTC 10 Jan 1998 of (a),(b) freezing rain and (c),(d) total solid precipitation. Also shown are the locations of the four subregions $\mathrm{A}, \mathrm{B}, \mathrm{C}$, and D (squares).

portion that is shed back to rain (Morrison and Milbrandt 2015), whereas in P3_MOD they are transferred to $q_{i, \text { liq }}$ to form mixed-phase particles. These mixed-phase particles can refreeze if temperatures are below $0^{\circ} \mathrm{C}$ (Fig. 13f; near aloft the melting layer). In the example shown here, this impacts the cloud ice characteristics above the melting layer by decreasing the rime mass fraction (Fig. 12f), the number concentration and the total mass mixing ratio (Fig. 12c). This decrease of $q_{i, \text { tot }}$ and $F_{i, \text { rim }}$ above the melting layer in subregions $\mathrm{A}$ and $\mathrm{B}$ may be a consequence of a combination of processes, including feedbacks, as described above. First, the difference between P3_MOD and P3_ORIG at lower levels (e.g., in the melting layer) affects atmospheric variables (e.g., temperature, vertical motion), which impacts the ice content above the melting layer. Second, the difference in the treatment of the wet growth process, which is expected to be more gradual in P3_MOD than in P3_ORIG, leads to smaller $F_{i, \text { rim }}$ in P3_MOD. Finally, smaller $q_{i, \text { tot }}$ contributes to reducing the deposition rate on ice above the melting layer. These processes are particularly important when southerly winds aloft bring higher amounts of water vapor above the melting layer as in ME during the second icing period.

\section{Conclusions}

Simulating winter precipitation types is challenging because it involves parameterizing key microphysical processes associated with mixed-phase particles, such as partial melting and refreezing. To address this, a predicted bulk liquid fraction $F_{i, \text { liq }}$ was recently implemented into the Predicted Particle Properties (P3) bulk microphysics scheme (C19). This allows the explicit representation of mixed-phase particles and their processes. The objective was to investigate the impacts of predicting the bulk liquid fraction on simulated precipitation types and characteristics produced during a winter storm. To this end, WRF simulations of the 1998 Ice Storm using the P3 scheme with (P3_MOD) and without (P3_ORIG) the predicted bulk liquid fraction were conducted. 
Both simulations reasonably reproduced the observed storm meteorological conditions (e.g., temperature and winds). The prediction of $F_{i, \text { liq }}$ allowed P3_MOD to reproduce observed precipitation types of freezing rain, ice pellets and wet snow. An overall decrease of freezing rain accumulation occurred with the predicted $F_{i, \text { liq }}$ in P3_MOD compared to P3_ORIG, with decreases up to $\sim 30 \%$ in some regions where ice pellets and freezing rain were mixed in P3_MOD. This led to a small but consistent improvement in bias and RMSE for P3_MOD compared to P3_ORIG, relative to observations. It was shown that partial melting and refreezing processes affect the simulated precipitation types obtained at the surface by changing bulk properties of hydrometeors as they fall through the melting and refreezing layers. In particular, the increase in mean density and hence fall speed during melting, and the increase of mean particle size during refreezing led to an increase of solid and ice pellets precipitation accumulation in $\mathrm{P} 3$ _MOD, while smaller mean raindrop sizes from melting led to a decrease in freezing rain rate compared to P3_ORIG. Combined with the changes in hydrometeor properties with prediction of the bulk liquid fraction, this result is also partially caused by removing the implicit melting scaling factor for the change in $N_{\text {rain }}$ during melting in P3_MOD compared to P3_ORIG.

Despite illustrating that including the prediction of $F_{i, \text { liq }}$ in the microphysics scheme does indeed have a significant impact on the simulated surface precipitation types for this severe freezing rain event, this study has some noteworthy limitations. First, it is challenging to validate the precipitation type during winter storms when temperatures are near $0^{\circ} \mathrm{C}$ (Ralph et al. 2005; Reeves et al. 2014), particularly because ice pellets are often not reported. Moreover, freezing rain and ice pellet events generally last only a few hours (e.g., Ressler et al. 2012; Matte et al. 2019). Therefore, hightemporal-resolution observations of surface precipitation type and measurements of the vertical temperature and relative humidity profiles are needed. Second, P3_MOD underpredicted the total solid accumulation (including ice pellets) in southern Quebec (near YUL) compared to hourly observed surface precipitation type. Other microphysical processes such as the secondary ice production (e.g., Hallett and Mossop 1974), which was not included here due to the use of a single ice-phase category in the P3 configuration, may have played an important role in the formation of ice pellets during the 1998 Ice Storm. This aspect could be investigated using the multiple category configuration of P3 (Milbrandt and Morrison 2016), which includes secondary ice production, combined with the prediction of bulk liquid fraction. Also, further studies could be done on the representation of ice pellets when the surface temperature is $>0^{\circ} \mathrm{C}$ and the information on the rime mass fraction could be use in addition to the liquid fraction to establish the surface precipitation type. Finally, the storm studied was extreme in terms of both duration and amount of precipitation. Indeed, strong warm-air advection and the northeasterly cold winds near the surface contributed to maintaining favorable conditions for freezing rain and ice pellets for a very long duration (H11). It would be interesting to compare P3_MOD and P3_ORIG when the vertical temperature structure is closer to $0^{\circ} \mathrm{C}$ (i.e., a weaker melting layer) and the diabatic cooling from melting and warming from refreezing rates are on the same order of magnitude as the warm-/cold-air advection.

Overall, this work is a step forward to a better understanding of the microphysical processes responsible for the formation of ice pellets and freezing rain during winter storms when temperatures are near $0^{\circ} \mathrm{C}$. More complete atmospheric models can now be used to study the occurrences of winter precipitation types and their transitions as well as other physical processes that can lead to the production of freezing rain and ice pellets at the surface using the modified P3 scheme with the prediction of $F_{i, \text { liq. }}$. Furthermore, P3_MOD could be useful for operational NWP since the detailed prediction of precipitation types is challenging. For example, a sounding-based precipitation type diagnostic algorithm (Bourgouin 2000) is used to diagnose surface precipitation types (including freezing rain and ice pellets) in the High Resolution Deterministic Prediction System, the kilometer-scale Canadian NWP system (Milbrandt et al. 2016). P3_MOD should also improve the simulated reflectivity in the bright band region due to the explicit parameterization of partial melting because particle properties for wet snowflakes are different than those of raindrops (Szyrmer and Zawadzki 1999; H11). For instance, wet snowflakes have larger diameter, but smaller density and fall speed than raindrops. Also, wet particles have higher reflectivity than dry (completely frozen) particles due to the larger dielectric factor of liquid water than ice. The effect of predicting the liquid fraction of mixed-phase particles on the simulated bright band reflectivity will be examined in detail in a future study.

Acknowledgments. The authors thank the funding agencies, Canadian Network for Regional Climate and Weather Processes (CNRCWP) funded by the Natural Sciences and Engineering Research Council of Canada (NSERC) as well as the NSERC Discovery grant and a Canadian Research Chair Tier 2. The first author (MC) would like to thank Fonds de recherche du QuébecNature et technologies (FQRNT) for a fellowship. 
The computations were made on the supercomputer Cedar managed by Calcul Québec and Compute Canada.

Data availability statement. The public version of the Predicted Particle Properties (P3) bulk microphysics scheme (here called P3_ORIG) is available in the public Weather Research and Forecasting (WRF) Model v_3.9.1.1 (available online at https://www2.mmm.ucar.edu/ wrf/users/download/get_sources.html\#WRF-ARW). This version of the $\mathrm{P} 3$ scheme has been modified to include the prediction of the bulk liquid fraction of mixed-phase particles (here called P3_MOD) following Cholette et al. (2019). The initial and lateral boundary conditions of North American Regional Reanalysis (NARR) are available online at https://www.ncdc.noaa.gov/data-access/ model-data/model-datasets/north-american-regionalreanalysis-narr. The model output files as well as the namelists of the model configuration are available upon request to the corresponding author (Melissa Cholette). Total accumulated precipitation types are from Milton and Bourque (1999). Soundings and surface fields are from the University of Wyoming web site (http:// weather.uwyo.edu/).

\section{APPENDIX}

\section{Microphysical Process Differences between P3_MOD and P3_ORIG}

Here we briefly describe differences in the microphysical processes between the original P3 scheme (P3_ORIG) and the modified version with the predicted bulk liquid fraction (P3_MOD). For details see C19.

First, the melting source/sink term is divided into two terms in P3_MOD. The first term is the melted water transferred into rain (i.e., into $q_{\text {rain }}$ ) from the complete melting of small spherical ice particles (Rasmussen et al. 1984a) and the second term is the melted water that accumulates on ice (i.e., into $q_{i, \text { liq }}$ ) (Fujiyoshi 1986). In P3_ORIG, all the melted water mass produced in a time step is instantaneously transferred to rain mass. A scaled number for rain source number mass mixing ratio $\left(N_{\text {rain }}\right)$ of 0.2 is applied in P3_ORIG to account for rapid evaporation of small melting ice particles. This melting scaling factor in P3_ORIG reduces the increase in $N_{\text {rain }}$ from melting and is based on the assumption that the smallest ice particles will melt first, producing small drops that will quickly evaporate and thus not contribute to the increase of $N_{\text {rain. }}$. No such scaling is applied in P3 MOD because evaporation/condensation of melting ice is explicitly treated as a separate process. When $F_{i, \text { liq }}>$ 0.99 in P3_MOD, all the remaining ice mass and number are transferred to rain.
Second, the refreezing process in P3_MOD gives the rate of accumulated water that refreezes when mixedphase particles enter cold layers $\left(T<0^{\circ} \mathrm{C}\right)$. The refreezing is computed with Pruppacher and Klett (1997) using relations for the capacitance and the ventilation coefficient that include both the ice and the liquid components of mixed-phase particles (C19). This process is not included in P3_ORIG. In P3_MOD, the mass of mixed-phase particles that refreeze from $q_{i, \text { liq }}$ in one time step is transferred to $q_{i, \text { rim }}(\mathrm{C} 19)$.

Third, at $T>0^{\circ} \mathrm{C}$, the mass of rain and cloud droplets that collide with ice is shed assuming a shed drop of $1 \mathrm{~mm}$ following Rasmussen et al. (1984b) in P3_ORIG, whereas, in P3_MOD, the collected liquid mass is accumulated in $q_{i, \text { liq }}$ and a fraction of it may subsequently be shed as described below.

Fourth, at $T<0^{\circ} \mathrm{C}$ and in wet growth situations in $\mathrm{P} 3$ ORIG, not all of the collected liquid water is frozen and some fraction is shed instead (Musil 1970). When wet growth conditions are diagnosed in P3_MOD, the collected rain and cloud mass is transferred to $q_{i, \text { liq }}$ and a part of it is subsequently shed.

Fifth, in P3_ORIG, shedding occurs with the collection and wet growth processes when $T<0^{\circ} \mathrm{C}$ while shedding from melting is neglected. In P3_MOD, shedding from both melting and wet growth occurs when $F_{i \text {,rim }}>0$ (i.e., for rimed particles) and it is assumed that only ice particles with diameters $>9 \mathrm{~mm}$ within the PSD shed accumulated liquid water following Rasmussen et al. (1984b).

Sixth, for simplicity, deposition/sublimation of ice in P3_MOD is allowed only when $F_{i, \text { liq }}=0$ because liquid water is assumed to be distributed evenly around the ice core when $F_{i \text {,liq }}>0$. When $F_{i \text {,iq }}>0$, particles undergo condensation/evaporation of the liquid mass mixing ratio $q_{i, \text { liq }}$. Note that the sublimation/deposition and the condensation/evaporation processes can occur at any temperature in P3_MOD, whereas in P3_ORIG the sublimation/deposition of ice is allowed only at $T<0^{\circ} \mathrm{C}$ and condensation/evaporation of melting particles is neglected.

Other ice-phase processes, such as self-aggregation and crystal nucleation (at temperatures $<-15^{\circ} \mathrm{C}$ ), are parameterized as described in Morrison and Milbrandt (2015) in both P3_MOD and P3_ORIG. The variables $q_{i, \text { liq }}, q_{i, \text { tot }}, q_{i, \text { rim }}$ and $B_{i, \text { rim }}$ use the total mass-weighted fall speed for their sedimentation, while $N_{i, \text { tot }}$ uses the numberweighted fall speed in both P3_ORIG and P3_MOD. However, an increase in both fall speeds occurs with increasing $F_{i, \text { liq }}$ in P3_MOD compared to P3_ORIG associated with the increase in particle density associated with $F_{i, \text { liq }}>0$ for mixed-phase particles in P3_MOD. The diagnostic variables, such as the mean mass-weighted density, the mean mass-weighted diameter, the reflectivity and 
the ice effective radius as well as the self-aggregation process are calculated using the size distributions and properties for whole mixed-phase particles, as for the refreezing and the condensation/evaporation processes. This means that the PSD accounts for both the ice and the liquid components of mixed-phase particles. In P3_ORIG, these variables are computed only with the dry ice properties.

Liquid-phase processes, such as droplet nucleation, condensation/evaporation, autoconversion, accretion, self-collection, and breakup of raindrops, are the same in P3_ORIG and in P3_MOD (see Morrison and Milbrandt 2015). Homogenous and heterogenous freezing of cloud droplets and rain are parameterized the same in both P3_MOD and P3_ORIG as described in Morrison and Milbrandt (2015). Homogenous and heterogenous freezing of cloud droplets and rain can occur at temperature below $-40^{\circ}$ and $-4^{\circ} \mathrm{C}$, respectively.

\section{REFERENCES}

Arnott, J. M., and J. Chamberlain, 2014: Lake-effect freezing drizzle: A case-study analysis. J. Oper. Meteor., 2, 180-190, https://doi.org/10.15191/nwajom.2014.0215.

Barszcz, A., J. A. Milbrandt, and J. M. Thériault, 2018: Improving the explicit prediction of freezing rain in a kilometer-scale numerical weather prediction model. Wea. Forecasting, 33, 767-782, https://doi.org/10.1175/WAF-D-17-0136.1.

Benjamin, S. G., J. M. Brown, and T. G. Smirnova, 2016: Explicit precipitation-type diagnosis from a model using a mixedphase bulk cloud-precipitation microphysics parameterization. Wea. Forecasting, 31, 609-619, https://doi.org/10.1175/ WAF-D-15-0136.1.

Bourgouin, P., 2000: A method to determine precipitation types. Wea. Forecasting, 15, 583-592, https://doi.org/10.1175/15200434(2000)015<0583:AMTDPT>2.0.CO;2.

Carmichael, H. E., R. E. Stewart, W. Henson, and J. M. Thériault, 2011: Environmental conditions favoring ice pellet aggregation. Atmos. Res., 101, 844-851, https://doi.org/10.1016/ j.atmosres.2011.05.015.

Chang, S. E., T. L. McDaniels, J. Mikawoz, and K. Peterson, 2007: Infrastructure failure interdependencies in extreme events: Power outage consequences in the 1998 Ice Storm. Nat. Hazards, 41, 337-358, https://doi.org/10.1007/s11069-006-9039-4.

Cheng, C. S., H. Auld, G. Li, J. Klaassen, B. Tugwood, and Q. Li, 2004: An automated synoptic typing procedure to predict freezing rain: An application to Ottawa, Ontario, Canada. Wea. Forecasting, 19, 751-768, https://doi.org/10.1175/15200434(2004)019<0751:AASTPT>2.0.CO;2.

Cholette, M., H. Morrison, J. A. Milbrandt, and J. M. Thériault, 2019: Parameterization of the bulk liquid fraction on mixedphase particles in the predicted particle properties (P3) scheme: Description and idealized simulations. J. Atmos. Sci., 76, 561-582, https://doi.org/10.1175/JAS-D-18-0278.1.

Cober, C. G., G. A. Isaac, and W. Strapp, 2001: Characterizations of aircraft icing environments that include supercooled large drops. J. Appl. Meteor., 40, 1984-2002, https://doi.org/10.1175/ 1520-0450(2001)040<1984:COAIET > 2.0.CO;2.

Descurieux, J., 2010: Post hoc evaluation of hazardous weather: Snowstorms in the Montréal, Québec, area in March 2008. Wea. Climate Soc., 2, 36-43, https://doi.org/10.1175/2009WCAS1018.1.
Dudhia, J., 1996: A multi-layer soil temperature model for MM5. Preprints, Sixth PSU/NCAR Mesoscale Model Users' Workshop, Boulder, CO, National Center for Atmospheric Research, 49-50.

Finch, Z., 2011: Forecasting freezing drizzle: The 3-4 February 2011 ice storm event in Corpus Christi, Texas. National Weather Service Tech. Rep., 19 pp., https://www.weather.gov/media/ crp/Feb2011_IceStorm.pdf.

Forbes, R., I. Tsonevsky, T. Hewson, and M. Leutbecher, 2014: Towards predicting high-impact freezing rain events. ECMWF Newsletter, No. 141, ECMWF, Reading, United Kingdom, 15-21, https://www.ecmwf.int/node/17334.

Frick, C., A. Seifert, and H. Wernli, 2013: A bulk parameterization of melting snowflakes with explicit liquid water fraction for the COSMO model. Geosci. Model Dev., 6, 1925-1939, https:// doi.org/10.5194/gmd-6-1925-2013.

Fujiyoshi, Y., 1986: Melting snowflakes. J. Atmos. Sci., 43, 307-311, https://doi.org/10.1175/1520-0469(1986)043<0307:MS>2.0.CO;2.

Gascón, E., T. Hewson, and T. Haiden, 2018: Improving predictions of precipitation type at the surface: Description and verification of two new products from the ECMWF ensemble. Wea. Forecasting, 33, 89-108, https://doi.org/10.1175/WAF-D-17-0114.1.

Gibson, S. R., and R. E. Stewart, 2007: Observations of ice pellets during winter storm. Atmos. Res., 85, 64-76, https://doi.org/ 10.1016/j.atmosres.2006.11.004.

Gyakum, J. R., and P. J. Roebber, 2001: The 1998 ice storm-Analysis of a planetary-scale event. Mon. Wea. Rev., 129, 2983-2997, https:// doi.org/10.1175/1520-0493(2001)129<2983:TISAOA>2.0.CO;2.

Hallett, J., and S. C. Mossop, 1974: Production of secondary ice particles during the riming process. Nature, 249, 26-28, https:// doi.org/10.1038/249026a0.

Hanesiak, J. M., and R. E. Stewart, 1995: The mesoscale and microscale structure of a severe ice pellet storm. Mon. Wea. Rev., 123, 3144-3162, https://doi.org/10.1175/1520-0493(1995)123<3144: TMAMSO $>2.0 . \mathrm{CO} ; 2$.

Henson, W., R. E. Stewart, and B. Kochtubajda, 2007: On the precipitation and related features of the 1998 Ice Storm in the Montréal area. Atmos. Res., 83, 36-54, https://doi.org/10.1016/ j.atmosres.2006.03.006.

,,--- , and J. M. Thériault, 2011: The 1998 Ice Storm: Local flow fields and linkages to precipitation. Atmos. Res., 101, 852-862, https://doi.org/10.1016/j.atmosres.2011.05.014.

Heymsfield, A. J., 2003: Properties of tropical and midlatitude ice cloud particle ensembles. Part II: Applications for mesoscale and climate models. J. Atmos. Sci., 60, 2592-2611, https://doi.org/ 10.1175/1520-0469(2003)060<2592:POTAMI > 2.0.CO;2.

Hindmarsh, J. P., A. B. Russell, and X. D. Chen, 2003: Experimental and numerical analysis of the temperature transition of a suspended freezing water droplet. Int. J. Heat Mass Transf., 46, 1199-1213, https://doi.org/10.1016/S0017-9310(02)00399-X.

Hong, S.-Y., N. Yign, and J. Dudhia, 2006: A new vertical diffusion package with an explicit treatment of entrainment processes. Mon. Wea. Rev., 134, 2318-2341, https://doi.org/ 10.1175/MWR3199.1.

Hosek, J., P. Musilek, E. Lozowski, and P. Pytlak, 2011: Forecasting severe ice storms using numerical weather prediction: The March 2010 Newfoundland event. Nat. Hazards Earth Syst. Sci., 11, 587-595, https://doi.org/10.5194/nhess-11-587-2011.

Hux, J. D., P. C. Knappenberger, P. J. Michaels, P. J. Stenger, H. D. Cobb III, and M. P. Rusnak, 2001: Development of a Discriminant Analysis Mixed Precipitation (DAMP) forecast model for mid-Atlantic winter storms. Wea. Forecasting, 16, 248-259, https://doi.org/10.1175/1520-0434(2001)016<0248: DOADAM $>2.0 . \mathrm{CO} ; 2$. 
Iacono, M. J., J. S. Delamere, E. J. Mlawer, M. W. Shephard, S. A. Clough, and W. D. Collins, 2008: Radiative forcing by long-lives greenhouse gases: Calculations with the AER radiative transfer models. J. Geophys. Res., 113, D13103, https://doi.org/10.1029/ 2008JD009944.

Ikeda, K., M. Steiner, and G. Thompson, 2017: Examination of mixed-phase precipitation forecasts from the High-Resolution Rapid Refresh model using surface observations and sounding data. Wea. Forecasting, 32, 949-967, https://doi.org/10.1175/ WAF-D-16-0171.1.

King, S., and D. P. Laplante, 2005: The effects of prenatal maternal stress on children's cognitive development: Project Ice Storm. Stress, 8, 35-45, https://doi.org/10.1080/ 10253890500108391.

Kringlebotn Nygaard, B. E., H. Ágústsson, and K. Somfalvi-Tóth, 2013: Modeling wet snow accretion on power lines: Improvements to previous methods using 50 years of observations. J. Appl. Meteor. Climatol., 52, 2189-2203, https://doi.org/10.1175/JAMC-D-120332.1.

Kumjian, M. R., and A. D. Schenkman, 2014: The curious case of ice pellets over middle Tennessee on 1 March 2014. J. Oper. Meteor., 2, 209-213, https://doi.org/10.15191/nwajom.2014.0217.

Laflamme, J. N., and G. Périard, 1998: The climate of freezing rain over the province of Québec in Canada: A preliminary analysis. Atmos. Res., 46, 99-111, https://doi.org/10.1016/S01698095(97)00054-9.

Landolt, S. D., J. S. Lave, D. Jacobson, A. Gaydos, S. DiVito, and D. Porter, 2019: The impacts of automation on present weather-type observing capabilities across the conterminous United States. J. Appl. Meteor. Climatol., 58, 2699-2715, https://doi.org/10.1175/JAMC-D-19-0170.1.

Lecompte, E. L., J. W. Russell, and A. W. Pang, 1998: La tempête de verglas de 1998. Institut de Prévention des Sinistres Catastrophiques Tech. Rep., 45 pp., https://www.iclr.org/wpcontent/uploads/PDFS/1998_ice_storm_report_french.pdf.

Matte, D., R. Laprise, J. M. Thériault, and P. Lucas-Picher, 2017: Spatial spin-up of fine scales in a regional climate model simulation driven by low-resolution boundary conditions. Climate Dyn., 49, 563-574, https://doi.org/10.1007/ s00382-016-3358-2.

__ J. M. Thériault, and R. Laprise, 2019: Mixed precipitation occurrences over southern Québec, Canada, under warmer climate conditions using a regional climate model. Climate Dyn., 53, 1125-1141, https://doi.org/10.1007/S00382-018-4231-2.

Mesinger, F., and Coauthors, 2006: North American Regional Reanalysis. Bull. Amer. Meteor. Soc., 87, 343-360, https:// doi.org/10.1175/BAMS-87-3-343.

Milbrandt, J. A., and M. K. Yau, 2005: A multimoment bulk microphysics parameterization. Part I: Analysis of the role of the spectral shape parameter. J. Atmos. Sci., 62, 3051-3064, https://doi.org/10.1175/JAS3534.1.

— physics based on the prediction of bulk ice particle properties. Part III: Introduction of multiple free categories. J. Atmos. Sci., 73, 975-995, https://doi.org/10.1175/JAS-D-15-0204.1.

— A. Glazer, and D. Jacob, 2012: Predicting the snow-to-liquid ratio of surface precipitation using a bulk microphysics scheme. Mon. Wea. Rev., 140, 2461-2476, https://doi.org/ 10.1175/MWR-D-11-00286.1.

, S. Bélair, M. Faucher, M. Vallée, M. L. Carrera, and A. Glazer, 2016: The pan-Canadian high resolution $(2.5 \mathrm{~km})$ deterministic prediction system. Wea. Forecasting, 31, 17911816, https://doi.org/10.1175/WAF-D-16-0035.1.
Milton, J., and A. Bourque, 1999: A climatological account of the January 1998 Ice Storm in Quebec. Environment Canada Tech. Rep. CES-Q99-01, 92 pp.

Morrison, H., and W. W. Grabowski, 2008: A novel approach for representing ice microphysics in models: Description and tests using a kinematic framework. J. Atmos. Sci., 65, 1528-1548, https://doi.org/10.1175/2007JAS2491.1.

_ physics based on the prediction of the bulk ice particle properties. Part I: Scheme description and idealized tests. J. Atmos. Sci., 72, 287-311, https://doi.org/10.1175/JAS-D-14-0065.1.

Musil, D. J., 1970: Computer modeling of hailstone growth in feeder clouds. J. Atmos. Sci., 27, 474-482, https://doi.org/ 10.1175/1520-0469(1970)027<0474:CMOHGI >2.0.CO;2.

Nagumo, N., A. Adachi, and H. Yamauchi, 2019: Geometrical properties of hydrometeors during the refreezing process and their effects on dual-polarized radar signals. Mon. Wea. Rev., 147, 1753-1768, https://doi.org/10.1175/MWR-D-18-0278.1.

Petrolito, A. W., 2005: The 2-3 January 2002 winter storm across central South Carolina and east central Georgia: A precipitation type case study. Eastern Region Technical Attachment 2005-02, 25 pp., https://www.weather.gov/media/erh/ta2005-02.pdf.

Pruppacher, H. R., and J. D. Klett, 1997: Microphysics of Clouds and Precipitation. Springer, $954 \mathrm{pp}$.

Ralph, F. M., and Coauthors, 2005: Improving short-term (0-48 h) coolseason quantitative precipitation forecasting: Recommendations from a USWRP workshop. Bull. Amer. Meteor. Soc., 86, 1619-1632, https://doi.org/10.1175/BAMS-86-11-1619.

Ramos da Silva, R., G. Bohrer, D. Werth, M. J. Otte, and R. Avissar, 2006: Sensitivity of ice storms in the southeastern United States to Atlantic SST-Insights from a case study of the December 2002 storm. Mon. Wea. Rev., 134, 1454-1464, https://doi.org/10.1175/MWR3127.1.

Rasmussen, R. M., V. Levizzani, and H. R. Pruppacher, 1984a: A wind tunnel and theoretical study of the melting behavior of atmospheric ice particles. Part II: A theoretical study for frozen drops of radius $<500 \mu \mathrm{m}$. J. Atmos. Sci., 41, 374-380, https://doi.org/ 10.1175/1520-0469(1984)041<0374:AWTATS > 2.0.CO;2.

,$- \ldots$, and $-1984 \mathrm{~b}$ : A wind tunnel and theoretical study of the melting behavior of atmospheric ice particles. Part III: Experiment and theory for spherical ice particles of radius $>$ $500 \mu \mathrm{m}$. J. Atmos. Sci., 41, 381-388, https://doi.org/10.1175/ 1520-0469(1984)041<0381:AWTATS > 2.0.CO;2.

Rauber, R. M., M. K. Ramamurthy, and A. Tokay, 1994: Synoptic and mesoscale structure of a severe freezing rain event: The St. Valentine's Day ice storm. Wea. Forecasting, 9, 183-208, https:/ doi.org/10.1175/1520-0434(1994)009<0183:SAMSOA > 2.0.CO;2.

Reeves, H. D., 2016: The uncertainty of precipitation-type observations and its effect on the validation of forecast precipitation type. Wea. Forecasting, 31, 1961-1971, https://doi.org/10.1175/ WAF-D-16-0068.1.

— K. K. Elmore, A. Ryzhkov, T. Schuur, and J. Krause, 2014: Sources of uncertainty in precipitation-type forecasting. Wea. Forecasting, 29, 936-953, https://doi.org/10.1175/WAF-D-1400007.1

_ _ A. V. Ryzhkov, and J. Krause, 2016: Discrimination between winter precipitation types based on spectral-bin microphysical modeling. J. Appl. Meteor. Climatol., 55, 1747-1761, https:// doi.org/10.1175/JAMC-D-16-0044.1.

Ressler, G. M., S. M. Milrad, E. H. Atallah, and J. R. Gyakum, 2012: Synoptic-scale analysis of freezing rain events in Montreal, Quebec, Canada. Wea. Forecasting, 27, 362-378, https://doi.org/ 10.1175/WAF-D-11-00071.1. 
Roebber, P. J., and J. R. Gyakum, 2003: Orographic influences on the mesoscale structure of the 1998 ice storm. Mon. Wea. Rev., 131, 27-50, https://doi.org/10.1175/1520-0493(2003)131<0027: OIOTMS $>2.0 . \mathrm{CO} ; 2$.

Schuur, T. J., H. S. Park, A. V. Ryzhkov, and H. D. Reeves, 2012: Classification of precipitation types during transitional winter weather using the RUC model and polarimetric radar retrievals. J. Appl. Meteor. Climatol., 51, 763-779, https:// doi.org/10.1175/JAMC-D-11-091.1.

Skamarock, W. C., and J. B. Klemp, 2008: A time-split nonhydrostatic atmospheric model for weather research and forecasting applications. J. Comput. Phys., 227, 3465-3485, https://doi.org/10.1016/j.jcp.2007.01.037.

Stewart, R. E., 1985: Precipitation types in winter storm. Pure Appl. Geophys., 123, 597-609, https://doi.org/10.1007/BF00877456.

_ J. M. Thériault, and W. Henson, 2015: On the characteristics of and processes producing winter precipitation types near $0^{\circ}$ C. Bull. Amer. Meteor. Soc., 96, 623-639, https://doi.org/ 10.1175/BAMS-D-14-00032.1.

Szyrmer, W., and I. Zawadzki, 1999: Modeling of the melting layer. Part I: Dynamics and microphysics. J. Atmos. Sci., 56, 3573-3592, https://doi.org/10.1175/1520-0469(1999) 056<3573:MOTMLP $>2.0 . \mathrm{CO} ; 2$.

Thériault, J. M., and R. E. Stewart, 2010: A parameterization of the microphysical processes forming many types of winter precipitation. J. Atmos. Sci., 67, 1492-1508, https://doi.org/10.1175/ 2009JAS3224.1.

_ _ - J. A. Milbrandt, and M. J. Yau, 2006: On the simulation of winter precipitation types. J. Geophys. Res., 111, D18202, https://doi.org/10.1029/2005JD006665.
,-- , and W. Henson, 2010: On the dependence of winter precipitation types on temperature, precipitation rate, and associated features. J. Appl. Meteor. Climatol., 49, 1429-1442, https://doi.org/10.1175/2010JAMC2321.1.

Thielke, T., 2018: Using advanced post-processing methods with the HRRR-TLE to improve the prediction of cold season precipitation type. M.S. thesis, Dept. of Atmospheric Science, University of Wisconsin-Milwaukee, $46 \mathrm{pp}$

Thompson, G., 2019: High Resolution Numerical Weather model forecasts of icing at the ground and in the air. Proc. Int. Workshop on Atmospheric Icing of Structures, Reykjavík, Iceland, IWAIS, 6 pp., https://iwais2019.is/images/Papers/ 042_iwais_thompson.pdf.

, P. R. Field, R. M. Rasmussen, and W. D. Hall, 2008: Explicit forecasts of winter precipitation using an improved bulk microphysics scheme. Part II: Implementation of a new snow parameterization. Mon. Wea. Rev., 136, 5095-5115, https:// doi.org/10.1175/2008MWR2387.1.

Tobin, D. M., and M. R. Kumjian, 2017: Polarimetric radar and surface-based precipitation-type observations of ice pellet to freezing rain transitions. Wea. Forecasting, 32, 2065-2082, https://doi.org/10.1175/WAF-D-17-0054.1.

Xu, M., G. Thompson, D. R. Adriaansen, and S. D. Landolt, 2019: On the value of time-lag-ensemble averaging to improve numerical model predictions of aircraft icing conditions. Wea. Forecasting, 34, 507-519, https://doi.org/10.1175/WAF-D-180087.1.

Zerr, R. J., 1997: Freezing rain: An observational and theoretical study. J. Appl. Meteor., 36,1647-1661, https://doi.org/10.1175/ 1520-0450(1997)036<1647:FRAOAT > 2.0.CO;2. 